\title{
UN PATRIMONIO OCULTO Y RECUPERADO. Los GRAFFiti DE LA IGLESIA DE SANTIAGo DE Peñalba (Peñalba de Santiago, León)
}

\author{
VANESSA Jimeno GuerRA* \\ Centro Universitario de Estudios Hispánicos. Hamilton College
}

\begin{abstract}
Resumen
Desde mediados del siglo pasado, han sido varios los investigadores que han recogido en publicaciones de diversa índole la existencia de algunos de los graffiti practicados en el interior de la iglesia altomedieval de Santiago de Peñalba (Peñalba de Santiago, León). A pesar de ello, los trabajos realizados sólo son visiones fragmentarias y selectivas del vasto conjunto de manifestaciones parietales que se han conservado. Por ello, el presente estudio realiza un análisis exhaustivo de la totalidad de graffiti practicados en dicho templo berciano. La mayor parte de ellos fueron incisos durante la Edad Media y las tipologías a las que pertenecen, así como las intenciones con las que fueron practicados, son muy variadas.
\end{abstract}

\section{Palabras clave}

Santiago de Peñalba; León; Graffiti; Edad Media; Manifestaciones parietales.

\begin{abstract}
Since the middle of the last century, a wide range of publications have included some of the graffiti made on the inside of the early medieval church of Santiago de Peñalba (Peñalba de Santiago, León) In spite of that, these studies only give a fragmented picture of the vast collection of parietal signs preserved. That is why this work makes an in-depth study of all of these graffiti. Most of them were engraved during the Middle Ages, and their types are very diverse as well as the purposes for which they were made.
\end{abstract}

\section{Keywords}

Santiago de Peñalba; León; Graffiti; Middle Ages: Parietal signs.

\section{Résumé}

Depuis le milieu du siècle dernier, nombreux sont les chercheurs qui ont signalé dans des publications variées l'existence de plusieurs des graffitis exécutés à l'intérieur de l'église de Santiago de Peñalba (Région de León), édifiée dans le haut Moyen Âge. Cependant, ces travaux n'offrent que des visions fragmentaires et sélectives du vaste ensemble de témoignages pariétaux qui ont été préservés. C'est pourquoi notre étude vise à réaliser une analyse exhaustive de la totalité des graffitis exécutés dans ce temple du Bierzo. Pour la plupart d'entre eux ils furent gravés pendant le Moyen Âge, et les typologies dont ils relèvent comme leur destination sont très variées.

\section{Mots clés}

Santiago de Peñalba; León; Graffiti; Moyen Âge; témoignages d'art pariétal.

* E-mail: vjimg@unileon.es. 
A raíz del estudio de los graffiti hallados en las cavidades altomedievales excavadas en el valle medio del Esla ${ }^{1}$, en el año 2011 nos apercibimos de la existencia de los que fueron practicados en el monasterio, también altomedieval y geográficamente cercano, de San Miguel de Escalada ${ }^{2}$. Como bien pusimos entonces de manifiesto, las similitudes entre las incisiones parietales realizadas en dichas cuevas artificiales y algunas de aquellas ejecutadas en los muros del templo del municipio gradefeño eran evidentes. Hoy, tiempo después, decidimos aumentar este corpus de grabados practicados en arquitecturas de la Alta Edad Media incorporando aquellos realizados en el interior de la iglesia de Santiago de Peñalba (Peñalba de Santiago, León) que, hasta la actualidad, constituyen el repertorio más variado y numeroso de todos los que se conservan en la provincia leonesa.

Desde que en 1956 Menéndez Pidal recogiese la existencia de graffiti en este templo berciano $^{3}$ y, posteriormente, en el año 2002 la Fundación de Patrimonio Histórico de Castilla y León retirase los revoques de los paramentos que cubrían un importante conjunto de pinturas murales y grabados que se encontraban ocultos ${ }^{4}$, han sido muchos los autores que han divulgado y analizado algunos de estos últimos con mayor o menor acierto 5 . La gran cantidad de graffiti que conservan estos muros ha suscitado que algunos investigadores hayan intentado realizar una lectura global de los mismos sin percatarse de que se trata de una manifestación parietal espontánea que está presente en la gran mayoría de los espacios arquitectónicos y que responde a los motivos de temática más variada, así como a diversas épocas históricas, por lo que no es posible establecer una

\footnotetext{
Vanessa Jimeno Guerra, Arquitectura excavada altomedieval en el valle medio del Esla, ed. Universidad de León, León, 2012. Me gustaría expresar mi agradecimiento a los doctores Joaquín García Nistal, Santiago Domínguez Sánchez y Etelvina Fernández González, miembros del Departamento de Patrimonio Artístico y Documental de la Universidad de León, así como al célebre historiador y arqueólogo balear, el doctor Guillém Rosselló Bordoy, por su inestimable ayuda en la realización de este estudio.

2 Vanessa Jimeno Guerra, "A propósito de los graffiti del templo de San Miguel de Escalada (León)", Estudios Humanísticos. Historia, 10 (2011), pp. 277-296.

3 José Menéndez Pidal, "Las pinturas prerrománicas de la iglesia de Santiago de Peñalba", Archivo Español de Arte, 29 (1956), p. 295.

4 Zoa Escudero Navarro, Joaquín García Álvarez y Alfonso León López, "Intervenciones en la iglesia mozárabe de Santiago de Peñalba (León)", Patrimonio Histórico de Castilla y León, 19 (2004), pp. 23-34.

5 David Gustavo López, "Los grabados mozárabes de Peñalba", Estudios Bercianos, 10 (1989), pp. 2128; Julio Manuel Vidal Encinas, "Los grabados murales de la iglesia mozárabe de Santiago de Peñalba", I Congres Internacional de gravats rupestres i murals, 1992; María Suárez-Inclán Y Ruiz De La Peña, "Los grabados de la iglesia mozárabe de Santiago de Peñalba en León", Patrimonio Histórico de Castilla y León, 26, (2006), pp. 13-15; Milagros Guardia Pons, "Los grafitos de la iglesia de Santiago de Peñalba. Scariphare et pingere en la Edad Media", Patrimonio Histórico de Castilla y León, 33 (2008), pp. 51-58; Artemio Manuel Martínez Tejera, La ecclesia de Peñalba de Santiago (El Bierzo, León). "Arquitectura de Fusión" del siglo X en el antiguo reino de León, ed. Asociación para el estudio y difusión del arte tardoantiguo y medieval, Madrid, 2010, pp. 156-158; Artemio Manuel Martínez Tejera, "Espititualidad. Anacoretas, monjes, obispos", Reino de León. Hombres, mujeres, poderes e ideas, Gerardo Boto Varela (dir.), ed. Edilesa, León, 2010, p. 199; José María Lorenzo Arribas, "Grafitos históricos. Peñalba de Santiago, palabras mayores", Centro Virtual Cervantes, publicado el 12/09/2013, consultado el 28/08/2014, http://cvc.cervantes.es/el_rinconete/anteriores/septiembre_13/12092013_01.htm, y José María Lorenzo Arribas, "Translatio in parietem. Dos grafitos medievales en las iglesias de San Millán de Suso (La Rioja) y Santiago de Peñalba (León)”, Medievalia, 16 (2013), pp. 91-102.
} 
explicación común a todos ellos. Argumentos tan insólitos y dispares como obra de peregrinos $^{6}$, muros usados como paneles experimentales de miniaturistas ${ }^{7}$ e, incluso, obra de monjes que se aburrían durante la oración ${ }^{8}$ han sido planteados hasta el momento. No obstante, y hasta el actual estudio, nunca se había realizado una reproducción completa de los grabados practicados en el interior de la iglesia, así como una clasificación tipológica y análisis exhaustivo de los mismos, motivo por el que emprendemos el siguiente trabajo (Figuras 1 y 2).

FIGURA 1

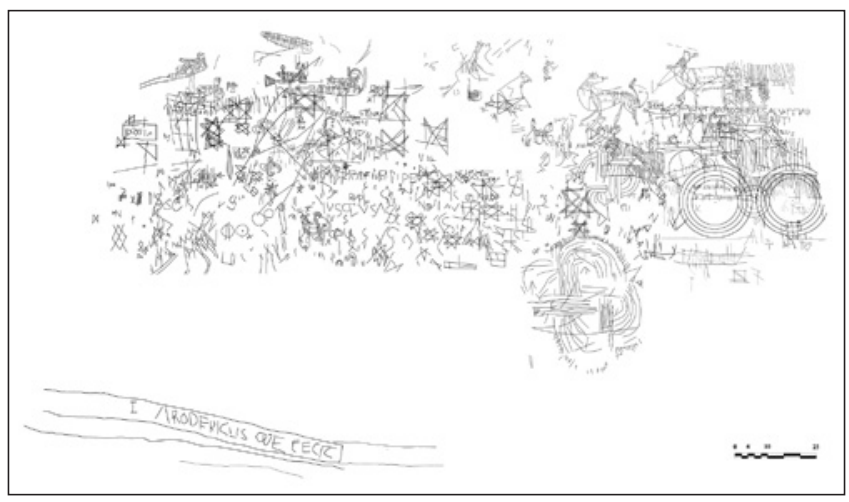

FIGURA 2

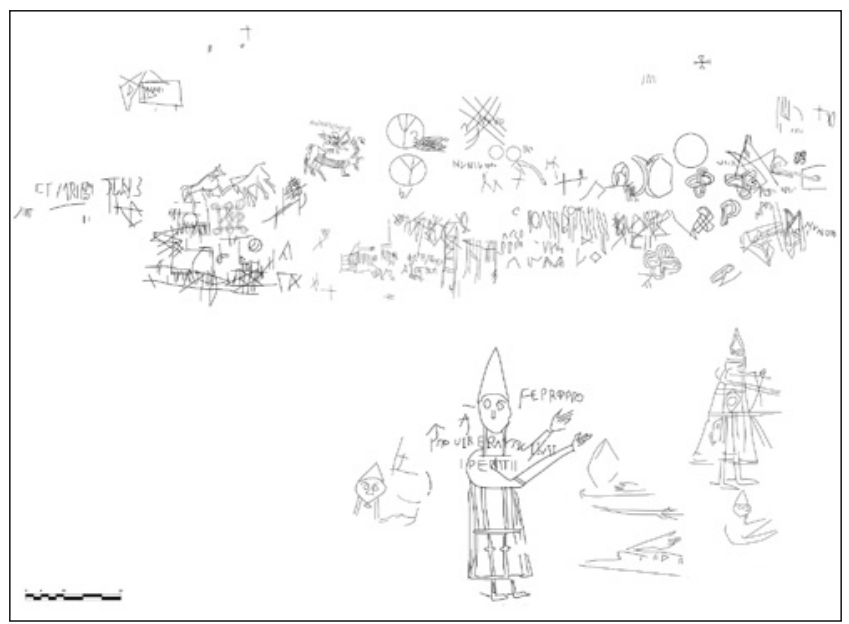

José MenÉndez Pidal, “Las pinturas..., p. 295.

David Gustavo López, "Los grabados..., pp. 27-28.

8 Milagros Guardia Pons, "Los grafitos..., p. 55 y José Miguel Lorenzo Arribas, "Grafitos históricos,... 


\section{Localización}

El lugar donde se emplazaba el antiguo coro es la parte de la iglesia donde se encuentra una mayor acumulación de grabados, aunque su presencia también es frecuente en el resto de los paramentos del templo. No obstante, a partir de la observación de éstos, intuimos que los graffiti conservados no fueron los únicos que se realizaron, ya que algunos de los practicados en el muro norte parecen estar fragmentados, además de existir un vacío de notable consideración entre estos y varios de los realizados en la parte baja del zócalo, lo cual es indicativo de una continuidad en las incisiones.

Aunque la mayor parte de los grabados se hallan al nivel de una persona en pie, bien es cierto que para la realización de algunos de ellos, sus artífices tuvieron que hacer uso de algún tipo de estructura de elevación.

\section{Tipologías}

Los motivos representados son diversos y responden a tipologías comunes en el ámbito de los graffiti, por lo que su clasificación en grupos facilitará su comprensión. No obstante, en algunas ocasiones, nos hemos visto obligados a introducir en un mismo apartado graffiti de distinta naturaleza por la evidente conexión que existe entre ellos. Este es el caso de las relaciones entre antropomorfos y zoomorfos, así como antropomorfos con motivos epigráficos.

\subsection{Motivos Geométricos}

Como viene siendo habitual en otros espacios del territorio peninsular, los graffiti geométricos son las representaciones más abundantes debido, probablemente, a la frecuencia con la que el hombre ha manifestado su interés por realizar diseños de esta índole.

En la iglesia de Santiago de Peñalba encontramos cuatro tipos de graffiti geométricos bien diferenciados y que hemos agrupado de la siguiente manera:

\subsubsection{Esteliformes}

Amén de las omnipresentes pentalfas9, el muro norte de Santiago de Peñalba es un buen escaparate de representaciones de carácter esteliforme de diferentes tamaños y grosores que, generalmente, responden a un modelo de estrella de ocho puntas formado a partir de dos cuadrados superpuestos en ángulo de 45 grados (Fig. 3). Graffiti similares se conservan en el monasterio de San Millán de Suso ${ }^{10}$, sobre el revoco románico de la iglesia de San

9 En el estudio sobre los graffiti de San Miguel de Escalada apuntábamos la dilatada presencia en el
tiempo de este motivo, así como su universalidad. Vid. Vanessa Jimeno Guerra, "A propósito...", p. 282.
10 Son 9 estrellas de ocho puntas las recogidas en este monasterio, siendo más abundantes en los dos
pórticos. Miguel Ibáñez RodríguEz y Teodoro LeJARRÁGA NiETo, Los grafitos del monasterio de San Millán 


\section{FiguRA 3}

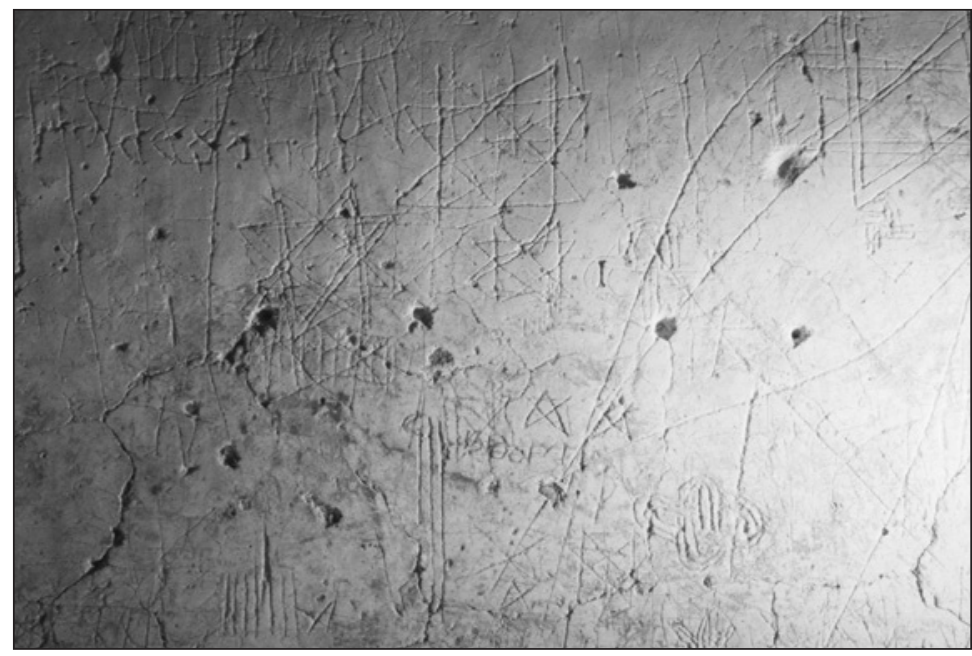

Miguel de San Esteban de Gormaz (Soria) ${ }^{11}$, en la torre del homenaje del Castillo de la Atalaya de Villena (Alicante) ${ }^{12}$ e, incluso, existen objetos medievales que adoptan esta forma, como el pinjante del Gabinete de Antigüedades de la Real Academia de la Historia, datado entre los siglos XIV-XV y para que el que se sugiere un uso como amuleto ${ }^{13}$. Algunos autores señalan que la estrella de ocho puntas "constituye uno de los signos más misteriosos, pues apenas si se conoce la verdadera significación del mismo", aunque, entre otras cosas, puede simbolizar "el equilibrio cósmico", así como "la regeneración, la resurrección y la vida eterna" ${ }^{14}$.

Una variante de esta estrella de ocho puntas, representada en tres ocasiones, se encuentra en el muro sur. Las únicas diferencias que poseen con respecto a las representadas en

de Suso, ed. Gobierno de La Rioja, Logroño, 1998, pp. 19, 85, 92, 95, 108 y 164.

11 VV. AA., "La piel que habla. Grafitos de los siglos XI-XIII sobre el revoco románico de la iglesia de San Miguel de San Esteban de Gormaz (Soria)", La memoria en la piedra. Estudios sobre grafitos históricos, Pablo Ozcáriz Gil (coord.), ed. Gobierno de Navarra, Navarra, 2012, p. 103.

12 Laura Hernández Alcaraz, "Los graffiti del castillo de la Atalaya (Villena, Alicante): un ejemplo de puesta en valor", en La memoria en la piedra, Estudios sobre grafitos históricos, Navarra, (2012), p. 116.

13 Jorge A. Eiroa Rodríguez, Antigüedades Medievales. Real Academia de la Historia. Catálogo del Gabinete de Antigüedades, ed. Real Academia de la Historia, Madrid, 2006, p. 108.

14 Manuel Monreal Casamayor, "De sermone heráldico IV: astros y meteoros", Emblemata, 10 (2004), p. 248 y 250. La estrella de ocho puntas aparece junto a otros símbolos como las pentalfas en la miniatura de La mujer sobre la bestia del Beato de Lorvao y, en este caso particular, han sido identificados como símbolos de uso supersticioso y mágico. Véase María de los Ángeles Sepúlveda González, "La mujer en el Comentario del Apocalípsis de Beato: La personificación de Babilonia y su interpretación", La condición de la mujer en la Edad Media: Actas del coloquio celebrado en la Casa Velázquez, del 5 al 7 de noviembre de 1984, ed. Universidad Complutense, Madrid, 1986, p. 415 y John Williams, The ilustrated beatus. A corpus of the illustrations of the comentary on the apocalypse. The twelfth and thirteenth centuries, ed. Harvey Miller, Londres, 2003, vol. 5. 
el muro norte es que sus extremos están redondeados, al igual que la imagen que recogimos en el intradós del arco formero situado entre el ábside central y el perteneciente a la nave del lado norte del templo de San Miguel de Escalada ${ }^{15}$. No obstante, como ya hemos puesto de manifiesto al comienzo de nuestro estudio cuando afirmábamos que no es posible establecer una idea general que justifique el origen de este conjunto tan amplio de grabados, en este caso, las semejanzas entre los motivos representados en distintas construcciones no implica que éstos posean la misma razón de ser y, por tanto, no es posible plantear la misma hipótesis para todos ellos. Así, mientras que en San Miguel de Escalada encontrábamos en la gran altura a la que realizó la estrella de ocho la justificación para relacionarla con un momento de la construcción del templo $\mathrm{y}$, por ende, con la decoración de la cubierta de madera de la nave, en Santiago de Peñalba esta argumentación no es válida, tanto por el emplazamiento bajo de los graffiti, como por la ausencia de elementos decorativos similares en las soluciones del techado del templo ${ }^{16}$. Lo que es evidente es que se trata de una tipología de graffiti muy abundante en construcciones de carácter religioso y civil tanto en la Península Ibérica como fuera de ella y de la que se han dado múltiples interpretaciones. Ejemplos de ello los encontramos en el monasterio de San Millán de Suso (La Rioja), reconocido como un habitual signo paleográfico medieval ${ }^{17}$, en la iglesia de Santa María de Ujué (Navarra), interpretado como una alegoría ${ }^{18}$, en el castillo de Almuñecar (Granada), al que se le atribuyen poderes mágicos y profilácticos ${ }^{19}$, e incluso fuera de nuestras fronteras como en la iglesia de Sta. Maria de Orria Pithinna (Sassari, Cerdeña) para la que Piras, además de señalar que puede ser una evidencia de elementos decorativos que forman parte de la propia construcción como en el caso de San Miguel de Escalada, incide de nuevo en esa posible función apotropaica del símbolo durante la época medieval y postmedieval ${ }^{20}$.

\footnotetext{
15 Vanessa Jimeno Guerra, “A propósito...”, pp. 282-283 y 291.

16 Gustavo López apunta la semejanza de estos motivos con "las molduras de algunos artesonados mudéjares de los siglos XIV al XVI", pero realmente lo interpreta "como la traslación a un plano del dibujo geométrico originado por las nervaduras de las bóvedas califales cordobesas del siglo X", opinión que no compartimos con el autor. David Gustavo López, "Los grabados..., p. 26. Una explicación a la cubrición del templo de Santiago de Peñalba mediante bóvedas se encuentra en Artemio Manuel Martínez Tejera, $L a$ ecclesia..., p. 145.

17 Miguel IbáÑez Rodríguez y Teodoro Lejárraga Nieto, Los grafitos..., pp. 27-28.

18 Pablo Ozcáriz, "Estudio de los grafitos", Santa María de Ujué, María Rosario Lazcano (coord.), ed. Fundación para la Conservación del Patrimonio Histórico de Navarra, Pamplona, 2011, p. 174.

19 José Ignacio Barrera Maturana, "Barcos, peces, estrellas y otros motivos en los muros del castillo de Almuñecar", Actes du XVII Colloque International de Glyptographie de Cracovie, del 4 al 10 de julio de 2010, Centre International de Recherches Glyptographiques, Bélgica, 2011, pp. 29 y 33-34.

20 Giuseppe PIras, "Le epigrafi, i segni lapidari e i graffiti", Villaggi e monasteri. Orria Pithinna. La chiesa, el villaggio, il monastero, Marco Milanese (coord.), ed. All'Insegna del Giglio, Florencia, 2012, pp. 68-69. Fernández del Cerro también señala que la estrella durante la Edad Media fue considerada como un elemento profiláctico y apotropaico, para lo que pone como ejemplo su aparición en manuscritos bajomedievales donde se combina la medicina con la magia blanca. Jacobo Fernández Del Cerro, "Abandono, reocupación y reforma de una casa hispanomusulmana entre los siglos XI y XIV. Los graffiti de la Calle Locum, 15 (Toledo)", La ciudad medieval de Toledo: historia, arqueología y rehabilitación de la casa. El edificio Madre de Dios: Universidad de Castilla La Mancha, Jean Passini y Ricardo Izquierdo Benito (coords.), ed. Universidad de Castilla la Mancha, Toledo, 2008, p. 134.
} 


\section{FIGURA 4}

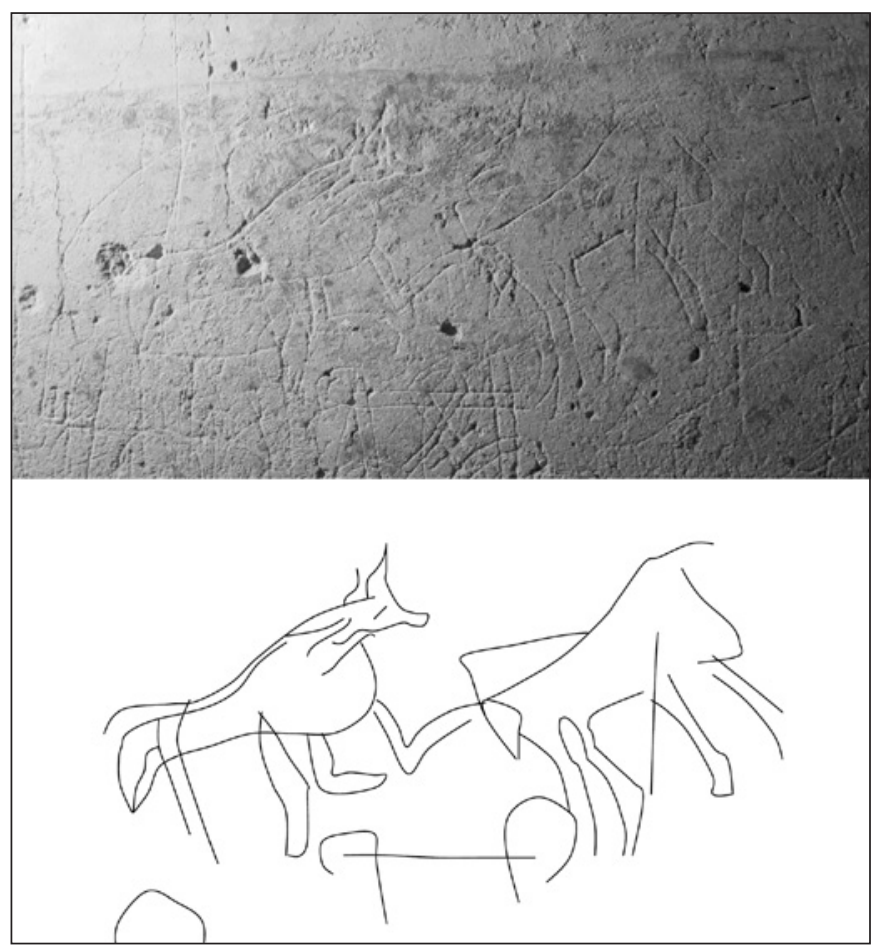

En nuestro caso, dos de las estrellas aparecen representadas de forma aislada mientras que otra se encuentra bajo una escena formada por dos animales en la que uno de ellos trata de dar caza al otro (Fig. 4), al igual que ocurre en el castillo de Alcañiz (Teruel), donde la estrella se sitúa junto a una escena cinegética. De esta manera, si extrapolamos la hipótesis planteada por Barrera Maturana, quien ha constatado "la asociación de estrellas y escenas de caza en otros grafitos medievales" y que atribuye a estas formas esteliformes la virtud de propiciar la suerte a alguno de los personajes que forman parte de la cacería ${ }^{21}$, en Santiago de Peñalba podría ser la ayuda para que el lobo se haga con su presa o, por el contrario, el talismán para que el otro cuadrúpedo pueda zafarse de él. No obstante, la universalidad de estos motivos geométricos básicos invita a analizar su reiteración más desde una perspectiva antropológica y "determinista" que desde una perspectiva histórica de transmisión de modelos $^{22}$.

21 José Ignacio Barrera Maturana, "Barcos, peces,...”, p. 34.

22 En este punto cabe recordar la existencia de dos posturas historiográficas enfrentadas en torno al origen de estos motivos geométricos que, en algunos casos, han sido utilizados como ornamentos. De una parte, la iniciada por Alois Riegl en su monografía Problemas de estilo, que sentaría las bases de una corriente de pensamiento que defiende el desarrollo evolutivo y la transferencia histórica de los motivos decorativos $\mathrm{y}$, de otra parte, la teoría "determinista" apadrinada por Gottfried Semper, para quien la reiteración de ornamentos básicos, especialmente de tipo geométrico, no atendería tanto a la copia y difusión de un modelo inicial 


\title{
2.1.2. Circulares
}

Los motivos circulares se localizan mayoritariamente en el muro norte formando un conjunto de graffiti cerrado en el que las formas realizadas a compás se inscriben unas dentro de otras e incluso se entrelazan.

Este tipo de incisiones son abundantes en construcciones de carácter heterogéneo datadas en periodos históricos dispares, por lo que, como venimos manifestando, algunos autores piensan que no puede establecerse un origen común a todas ellas ${ }^{23}$. En nuestra opinión, la mayor parte de estos grabados suelen responder a ensayos previos a la realización de una obra definitiva de carácter artístico en la propia construcción y, para el caso de Santiago de Peñalba, podrían estar en relación con la ornamentación pictórica de la bóveda que cubre la nave. De hecho, en el estudio que Guardia Pons ha realizado en referencia a estas pinturas datadas en el siglo $\mathrm{X}$, se explica que en su ejecución

\begin{abstract}
"se recurre, de forma insistente, a la incisión para determinar el diseño de los temas y composiciones ornamentales con un uso casi obsesivo del compás, del que restan marcas indelebles en la superficie definitiva y que permite, por tanto, restituir la composición pictórica en su esquema pese a que se haya perdido en diversas zonas la capa pictórica"24.
\end{abstract}

En este sentido, creemos necesario apuntar que en la cara este del contrafuerte emplazado en el lado sur del templo, marcando la separación entre el coro y la nave, se localiza un grabado que corresponde a una palmera, cuya perfecta ejecución evidencia su no pertenencia a este elenco de graffiti y sí al conjunto de pinturas murales (Fig. 5). No olvidemos que la representación de este fitomorfo es muy frecuente en la plástica medieval, tanto en el ámbito religioso como en el civil25. Se trata de una figura de tamaño notable e incisa con bastante precisión, como se puede observar,

como al origen antropológico y universal de los mismos por las determinaciones impuestas por técnicas y materiales. Para profundizar en ambas posturas, véase Alois RIEGL, Stilfragen. Grundlengungen zu einer Geschichte der Ornamentik, ed. Gerog Siemens Vergag, Berlin, 1893 y Gottfried SemPer, The four elements of architecture and other writings, ed. Cambridge University Press, Cambridge-New York, 1989.

23 Tomás Martín Rodríguez Cerezo, "Elementos permanentes en la iconografía de los grafitos: los círculos y rosetones realizados con compás", La memoria en la piedra. Estudios sobre grafitos históricos, Pablo Ozcáriz Gil (coord.), ed. Gobierno de Navarra, Navarra, 2012, p. 266.

24 Además, explica que se trata de un proceso utilizado ya en la antigüedad y del que existen ejemplos en la decoración pictórica de algunas iglesias asturianas, entre otros lugares. Milagros Guardia Pons, "De Peñalba de Santiago a San Baudelio de Berlanga. La pintura mural de los siglos X y XI en el Reino de León y Castilla. ¿Un espejo del Al-Andalus?”, El legado del Al-Andalus. El arte andalusí en los reinos de León y Castilla durante la Edad Media, Manuel Valdés Fernández (coord.), ed. Fundación del Patrimonio Histórico de Castilla y León, Valladolid, 2007, pp. 125-126.

25 Etelvina Fernández González, "Los árboles no dejan ver el bosque", Cuadernos del CEMYR, 21 (2013), p. 7. 
no sólo en la rectitud de las líneas con las que se realizó su tronco sino también en su copa, cuyas ramas y hojas están trazadas en el interior de una semicircunferencia ejecutada a compás. Este es un procedimiento habitual para las representaciones de palmeras en las miniaturas medievales, ejemplo de lo cual es la palma en torno a la que se encuentran Adán y Eva en el Codex Albeldense o Vigilano, en cuyo "diseño se empleó un trazo circular perfecto, realizado a compás, que aún se percibe; incluso el pequeño orificio generado por la aguja del referido instrumento es visible sobre la superficie del pergamino"26.

\section{FIGURA 5}

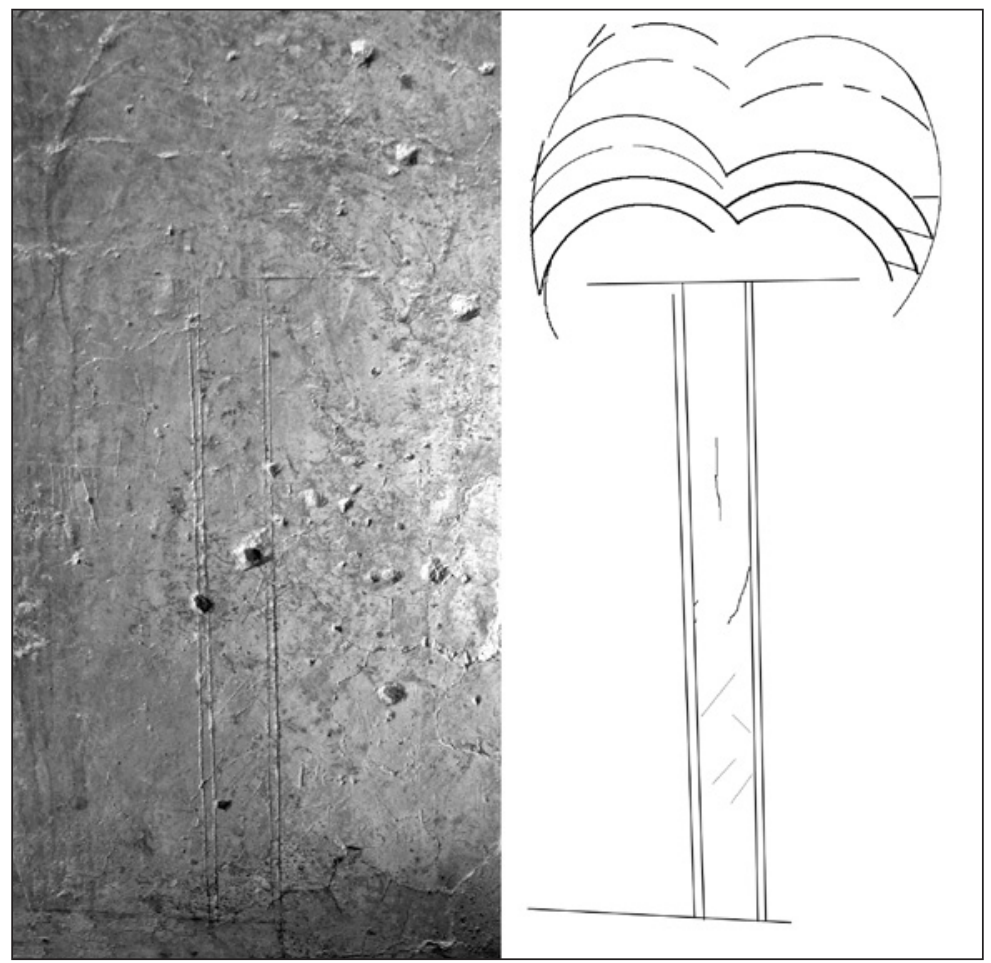

\subsubsection{Lineales}

Una buena parte de los muros de la iglesia están cubiertos de incisiones de carácter lineal que, en algunas ocasiones responden a grabados practicados sobre ellos,

26 Etelvina Fernández González y Fernando Galván Freile, "Iconografía, ornamentación y valor simbólico de la imagen. El «Códice Albeldense»", Imágenes de poder en la Edad Media. Selección de estudios del Prof. Dr. Fernando Galván Freile, Etelvina Fernández González (coord.), ed. Universidad de León, León, 2011, vol. 1, p. 239, nota 80 . 
mientras que en otras son simplemente el resultado de la acción del paso del tiempo. Es por ello que, para evitar errores innecesarios, los graffiti que recogemos en este apartado son aquellas incisiones que no plantean ninguna duda con respecto a su origen. No obstante, es bastante complicado establecer una correcta interpretación para los grabados lineales, ya que en la mayor parte de los casos son meras líneas representadas, bien de forma aislada, bien formando parte de una maraña sin un significado aparente ${ }^{27}$.

Existen otras representaciones que requieren mayor atención, puesto que son incisiones que se repiten en numerosos espacios arquitectónicos de carácter y cronología diversa. Este es el caso de las líneas verticales dispuestas de forma paralela y a intervalos regulares y que han sido identificadas en numerosas ocasiones con calendarios o elementos de contabilidad ${ }^{28}$. En la iglesia de Santiago de Peñalba se encuentran tanto en el muro norte como en el sur y, en algunos casos, incisas sobre grabados previos, lo cual nos indica una data post quem para éstas y que establecemos, al menos, con posterioridad al siglo XIII (Fig. 6) ${ }^{29}$.

\footnotetext{
27 Esta misma opinión es expresada por Arnaiz Alonso cuando dice que los graffiti lineales de San Miguel de Gormaz "están constituidos por grupos de líneas tangenciales y secantes, que no forman ninguna representación identificable con aspectos concretos" en Benito ArNaiz Alonso "La expresión espontánea: graffiti en San Miguel de Gormaz", San Miguel de Gormaz. Plan integral para la recuperación de un edificio histórico, Consuelo Escribano Velasco y Elena Heras Fernández (coords.), ed. Junta de Castilla y León, Valladolid, 2008, p. 194.

28 Navarro Poveda apunta que aparecen con bastante profusión tanto el Castillo de Petrer como en el de La Mola. De la misma manera, Barrera Maturana los recoge en una casa morisca del Albayzin (Granada), e incluso algunos autores los han reconocido en algunas cavidades. VV. AA., "Los graffiti más recientes de la cueva de La Camareta", Antigüedad y Cristianismo, 10 (1993), p. 428; Concepción Navarro Poveda, "Grafitos medievales del Castillo de Petrer y del Castillo de la Mola (Novelda) (Valle Medio del Vinalopó-Alicante)", I Congrés Internacional de Gravats Rupestres i Murals, Joan-Ramón González Pérez (coord.), ed. Institut D’Estudis Ilerdencs, Lleida, 2003, p. 742; José Ignacio Barrera Maturana, "Representación de una mujer morisca en un graffiti del Albayzin (Granada)", Anaquel de Estudios Árabes, 18 (2007), pp. 68 y 80. Fuera de nuestras fronteras, y con una cronología mucho más anterior, existen incisiones verticales con el mismo carácter en el vestíbulo de una casa pompeyana. Rebecca R. Benefiel, "Dialogues of Graffiti in the House of the Four Styles at Pompeii (Cada Dei Quattro Stili, I.8.17, 11)", Ancient Graffiti in Context, J. A. Baird y Claire Taylor (eds.), ed. Routledge, New York, 2012, pp. 37-41.

29 Estas líneas fueron realizadas en el muro norte sobre un león, una combinación de antropomorfo y équido y algunos graffiti epigráficos y geométricos, para los que establecemos cronologías a lo largo del presente estudio.
} 


\section{FIgURA 6}

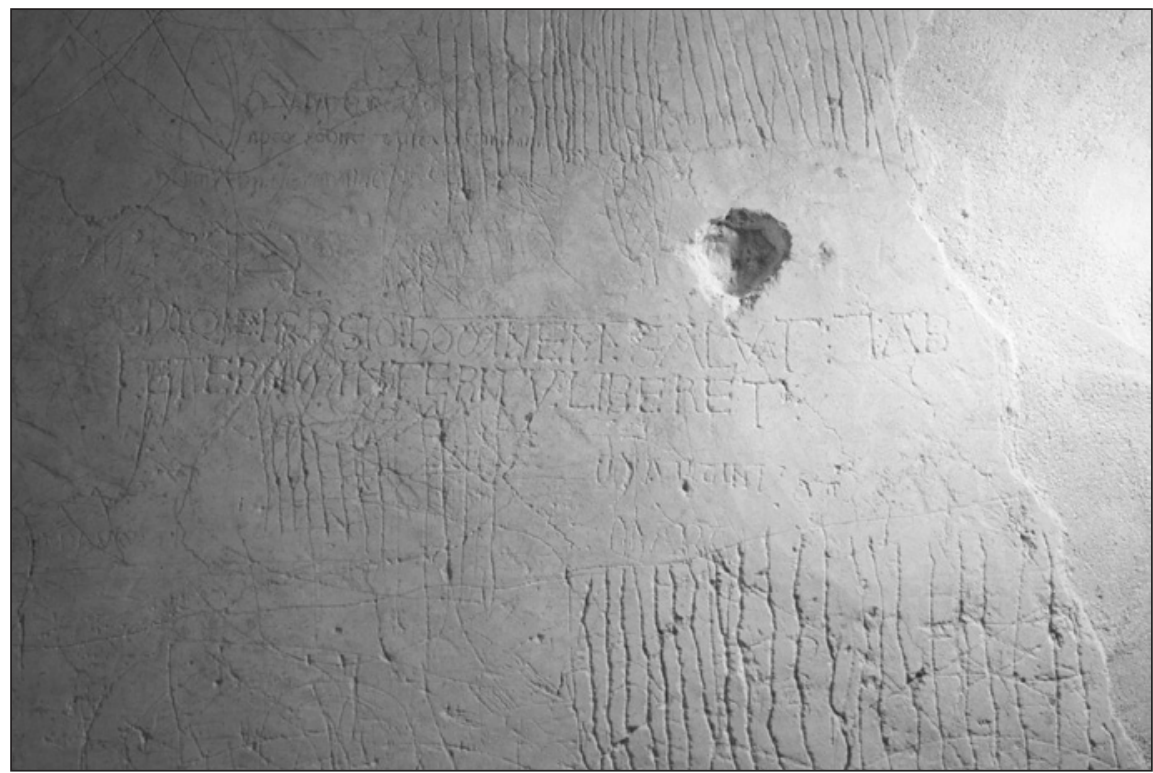

\subsubsection{Cruciformes}

A pesar de ser la cruz una de las tipologías de graffiti más numerosa en cualquier construcción de carácter religioso, en Santiago de Peñalba tan sólo se conserva la representación de algunas pequeñas cruces en el muro sur. Una de ellas es un claro ejemplo de cruz de brazos patados, semejante a la famosa Cruz de Peñalba que se conserva en el Museo de León, mientras que otra presenta una incisión mucho más simple, aunque cada uno de sus brazos está acentuado en sus extremos mediante una perforación redondeada, posible muestra del perfil de la herramienta con la que fue realizada. Asimismo, el punto en el que convergen los travesaños de esta última está marcado por una pequeña circunferencia a modo de nudo o disco central como las cruces de orfebrería y que, como señalan algunos autores, era una parte de la cruz que se ennoblecía porque era el "lugar de la cabeza del Salvador durante la crucifixión"30. De nuevo, la Cruz de Santiago de Peñalba es un claro ejemplo de ello ${ }^{31}$.

\footnotetext{
30 Achim Arbeiter y Lorenzo Arias PÁramo, "Condicionantes histórico-artísticos de las cruces de Oviedo y su posterior restauración", Territorio, Sociedad y Poder, 2 (2009), p. 411.

31 Para una mayor información sobre esta cruz, véase Rafael GonzÁlez Rodríguez, "La Cruz de Peñalba. Alma del Bierzo en cuerpo de latón”, Bierzo, (2010), pp. 5-27.
} 


\subsubsection{Nudos de Salomón}

Junto con los motivos esteliformes registrados, los nudos o lazos de Salomón, también conocidos como Swastika Pelta, constituyen uno de los graffiti más abundantes en Santiago de Peñalba con una amplia variedad de tamaños y complejidad en sus diseños. Hasta ocho grabados hemos contabilizado entre ambos muros, amén de los fragmentos que se pueden vislumbrar de algunos de ellos. Pero, sin lugar a dudas, es aquel inciso en el muro norte, con un tamaño de $39 \times 37 \mathrm{cms}$. y su contorno acentuado con pequeñas líneas dispuestas de forma radial, el que destaca sobre todos ellos (Fig. 7).

No hay lugar a dudas de que se trata de un motivo geométrico muy representado desde la cultura celta hasta la Edad $\mathrm{Media}^{32}$, periodo del que se conservan en la Península Ibérica importantes muestras, como los relieves que aparecen en las portadas y capiteles de algunas iglesias catalanas, tales como Santa María de Bell-lloc (Santa Coloma de Queralt) o Santa María de 1'Estany (Bages) ${ }^{33}$, entre otras. Mientras, en la esfera de los graffiti, los ejemplos también son frecuentes ${ }^{34}$, como aquel que aparece inciso en la cara inferior de un tablero de juego de la antigua Barcino del siglo II a.d.C..$^{35}$ o en los muros de algunas iglesias como las del Pla de Santa María (Tarragona) ${ }^{36}$, Santa María de Ujué (Navarra) ${ }^{37}$ o San Pelayo de Perazancas (Palencia), aunque en este último caso se ha interpretado como una marca de cantero ${ }^{38}$.

32 Juan Eduardo CirLot, Diccionario de símbolos, ed. Labor, Madrid, 2004, pp. 273-274. Son muy numerosos los mosaicos de época romana que utilizan este motivo en sus diseños, como por ejemplo el denominado "Mosaico de los nudos de Salomón" conservado en la casa n 3 de Clunia (Burgos) o el "Mosaico con ruedas de peltas" de la estancia LXI de la villa romana de El Ruedo (Córdoba), los cuales aparecen recogidos en Rafael Hidalgo Prieto, "Mosaicos con decoración geométrica y vegetal de la villa romana de El Ruedo (Almedinilla, Córdoba)", AAC2, (1991), pp. 326 y 356 y VV. AA., Corpus de mosaicos de España. Mosaicos romanos de Burgos, ed. CSIC, Madrid, 1998, vol. 12, p. 70.

33 Peter Hubert, "The origins of Interlace in Romanesque Sculpture", The green man of cercles, consultado el 20/08/2014, http://www.green-man-of-cercles.org/articles/origins_of_interlace_sculpture.pdf, pp. 31-34.

34 Asímismo lo señalan Pritchard y Champion para el ámbito inglés y recogen como ejemplos de ello aquellos conservados en las iglesias de St. John (Duxford), St. Mary the Virgin (Essex), St. Martin (Essex) y la consagrada a todos los santos en Litcham (Norfolk). Violet Pritchard, English Medieval Graffiti, ed. Cambridge University Press, London, 1967, pp. 33 y 83-85 y Matthew CHAmpion, "Medieval graffiti inscriptions found in All Saints' Church, Litcham", Norfolk Archaeology, 46 (2011), p. 201.

35 Esta pieza se conserva en el Museo de Historia de la Ciudad de Barcelona. Peter Hubert, "The origins..., pp. 31-32.

36 Peter Hubert, "The origins..., pp. 33-34.

37 Pablo Ozcáriz GiL, "Estudio de..., pp. 173-174.

38 Castiñeiras establece una relación entre este grabado en el muro exterior de la cabecera del templo con la forma que adopta la letra $\mathrm{O}$ en la inscripción colocada sobre la puerta norte del edificio para concluir sugiriendo que parece "una marca de taller", además de un motivo ornamental "propio de la miniatura hispánica del momento". Manuel Antonio CastiÑeIRAs GonzÁlez, "El Labora: los trabajos y los días en la iconografía románica", Vida y muerte en el monasterio románico. 17 Seminario sobre Historia del Monacato, José Ángel García de Cortazar y Ruíz Aguirre (coord.), ed. Fundación Santa María La Real. Centro de Estudios del Románico, Aguilar de Campoo, 2004, p. 73. 
A pesar de esta abundancia de representaciones, su significado varía en las distintas civilizaciones, además de no estar totalmente clarificado. No obstante, para el ámbito cristiano, algunos autores piensan que integra el simbolismo de la cruz y el laberinto, por lo que frecuentemente ha sido interpretado como "emblemas de la divina inescrutabilidad" 39 .

\section{FiguRA 7}

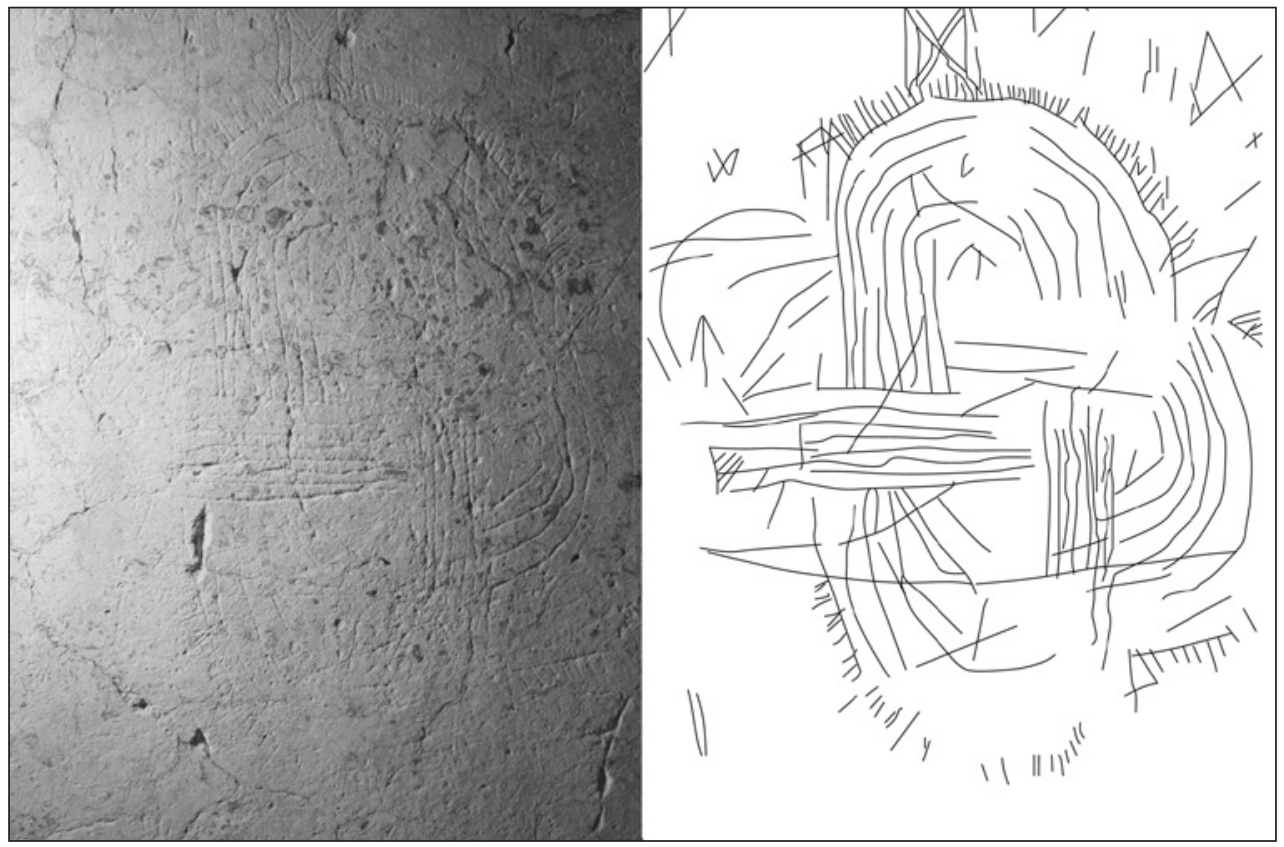

\subsection{Motivos Zoomorfos}

La mayor parte de los animales representados son perfectamente reconocibles e incluso algunos aparecen acompañados de cartelas que contribuyen a su correcta identificación. Este es el caso de la palabra $L E O$ situada junto a los dos leones incisos en el muro norte que recuerda a la misma inscripción que acompaña al león pintado en el intradós de uno de los arcos de la iglesia de San Juan de Boí (Lérida) ${ }^{40}$. Estas dos fieras fueron realizadas con las cabezas vueltas hacia su lomo y con la lengua fuera en uno de los casos. Su pelaje está insinuado de forma esquemática mediante líneas incisas en el cuello, aludiendo a su gran melena, patas traseras y cola, en la que incluso se representa la borla de pelo en su extremo.

39 Juan Eduardo Cirlot, Diccionario de..., p. 274.

40 En el ejemplo de Boí, la figura del león no se conserva en su totalidad, por lo que la inscripción contribuye en gran medida a la hora de determinar el animal representado. De la misma manera, fueron representados otros animales con sus correspondientes cartelas. 
Uno de los dos felinos, el de mejor factura, tiene practicada una inscripción sobre su lomo que algunos autores han recogido y transcrito erróneamente como CANIS ECBALIUS $S^{41}$ (Fig. 8). Es evidente que el estado de conservación de las grafías no es el deseado para poder efectuar una lectura adecuada, sin embargo, se observa con facilidad la inexistencia de cualquier tipo de letra antes de la sílaba $A N$, del mismo modo que, entre ésta última y la letra $S$, además de no existir nuevas grafías, se observa un espacio de cierto tamaño que permite inferir que se trata del comienzo de una nueva palabra ${ }^{42}$. De esta manera, el primer vocablo quedaría reducido a la palabra $A N$, a la cual acompañarían al menos dos más ${ }^{43}$ y que darían lugar a una frase de la que tan sólo hemos podido transcribir algunas de las grafías que la integran por no conservarse en su totalidad: $A N: S: E c[B$

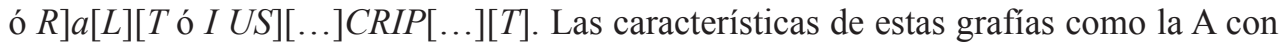
travesaño angular o el uso combinado de letras mayúsculas con otras minúsculas más o menos agrandadas no son extrañas en la epigrafía de la Alta Edad Media ${ }^{44}$.

Dentro de la extensa simbología animal que existe en la iconografía medieval, el león es uno de los animales de origen oriental más representados en las artes, formando parte de contextos tanto religiosos como profanos y que, por tanto, posee un carácter ambivalente que puede llevar a confusión ${ }^{45}$. A esto se suma, en el caso que nos ocupa, el mal estado de conservación del graffiti epigráfico que lo acompaña, de manera que la dificultad de su lectura nos impide precisar si existe una relación directa entre este motivo representado y el epigráfico. No obstante, es interesante señalar que en el muro opuesto se conserva la silueta de un león de tamaño notable realizada en pigmentos rojos y que formaría parte del repertorio de pinturas murales que decoraban el templo.

${ }^{41}$ Este es el caso de Guardia Pons que, incluso, apunta que dicha inscripción haría referencia a la constelación de Canis Maior. Milagros Guardia Pons, "Los grafitos..., p. 57. Posteriormente, Rodríguez Suárez recoge de forma literal la información aportada por Guardia Pons, además de identificar erróneamente al animal representado con un perro, para presentarlo como un ejemplo de impaginatio atípica. Natalia RodríGuez SuÁrez, "De la impaginatio codicológica a la impaginatio atípica", Impaginatio en las inscripciones medievales, Maria Encarnación Martín López y Vicente García Lobo (coords.), ed. Universidad de León, León, 2011, pp. 195-212.

42 En este punto nos gustaría recomendar el reconocimiento in situ de cualquier graffiti, ya que las fotografías, dependiendo del ángulo desde el cual están tomadas o la luz que hay en ese momento, no deben ser utilizadas como único testimonio.

43 A tenor de las líneas incisas en la pared, es evidente que la frase continuaría pero su lectura es prácticamente imposible.

44 Sobre letras minúsculas agrandadas, véase Juan Manuel SIERRA LóPEZ, El misal toledano de 1499, Instituto Teológico San Ildefonso, Toledo, 2004, p. 46 (nota 16); Javier De Santiago Fernández, "El hábito epigráfico en la Hispania visigoda", VIII Jornadas científicas sobre documentación de la Hispania altomedieval (siglos VI-X), Juan Carlos Galende Díaz y Javier de Santiago Fernández (dirs.), ed. Cema, Madrid, 2009, p. 300 y Ainoa Castro Correa, La escritura visigótica en Galicia. I. Diócesis lucense, Tesis Doctoral leída el 7 de julio de 2012, Departamento de Ciencias de la Antigüedad y de la Edad Media, Facultad de Filosofía y Letras, Universidad de Barcelona, pp. 429, 425 y 445, entre otras.

45 Véase la entrada Lion en Fernand CABrol y Henri LeCrercQ, Dictionnaire d'archéologia chrétienne et de liturgie, ed. Letouzey et Ané, París, 1950, t. 9/I, y Francisco De Asis García García, "El León”, Revista digital de iconografia medieval, 1 (2009), pp. 33-46. 


\section{FIgURA 8}

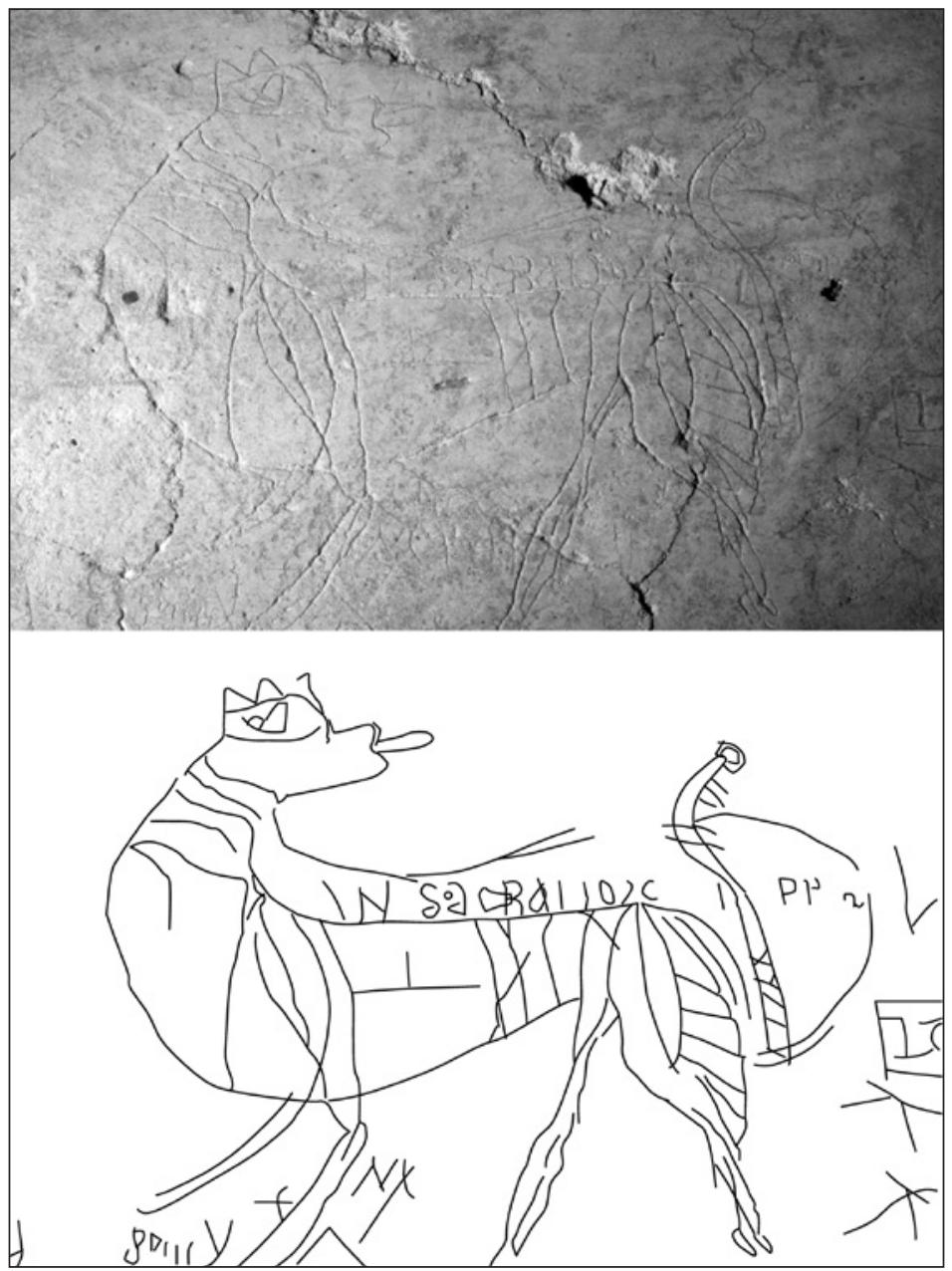

Otro de los animales representados es aquel que podríamos identificar con un pájaro y que se emplaza en el muro norte en número de 5 (Fig. 9). Su plumaje está insinuado a través de las líneas incisas en sus alas, cola y pecho e, incluso, algunos presentan plumas timoneras, y sus largas patas nos indican que nos encontramos ante zancudas. Sin embargo, el elemento discordante en el cuerpo de estas aves es la cabeza, la cual no parece corresponderse con la del animal en cuestión, no sólo por la ausencia de pico, sino porque parece tener rasgos humanos ${ }^{46}$. Además, mientras que el cuerpo de los ani-

\footnotetext{
46 Ya en 1989 Gustavo López apuntó la existencia de una cabeza humana tocada aunque, debido a que no se había retirado el encalado de la pared, la ubicó detrás un pez inexistente, el cual se correspondería con una parte del plumaje del pájaro. David Gustavo LóPEz, "Los grabados..., p. 27.
} 
males aparece representado de perfil, las cabezas están realizadas de forma frontal, con dos grandes cuencas oculares incisas, y, en algún caso, enmarcadas por una especie de tocado irreconocible, aspecto que recuerda en gran medida al rostro de San Lucas en la

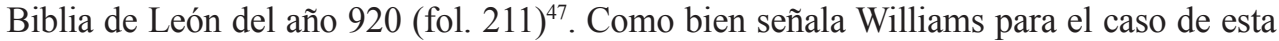
miniatura, durante la Alta Edad Media "la España cristiana no tenía una tradición esencial de las artes figurativas", por lo que se combinaban "vistas frontales y de perfil", lo cual podría ser extrapolable al caso que nos ocupa, de ser un graffito practicado en el siglo X.

FiguRA 9

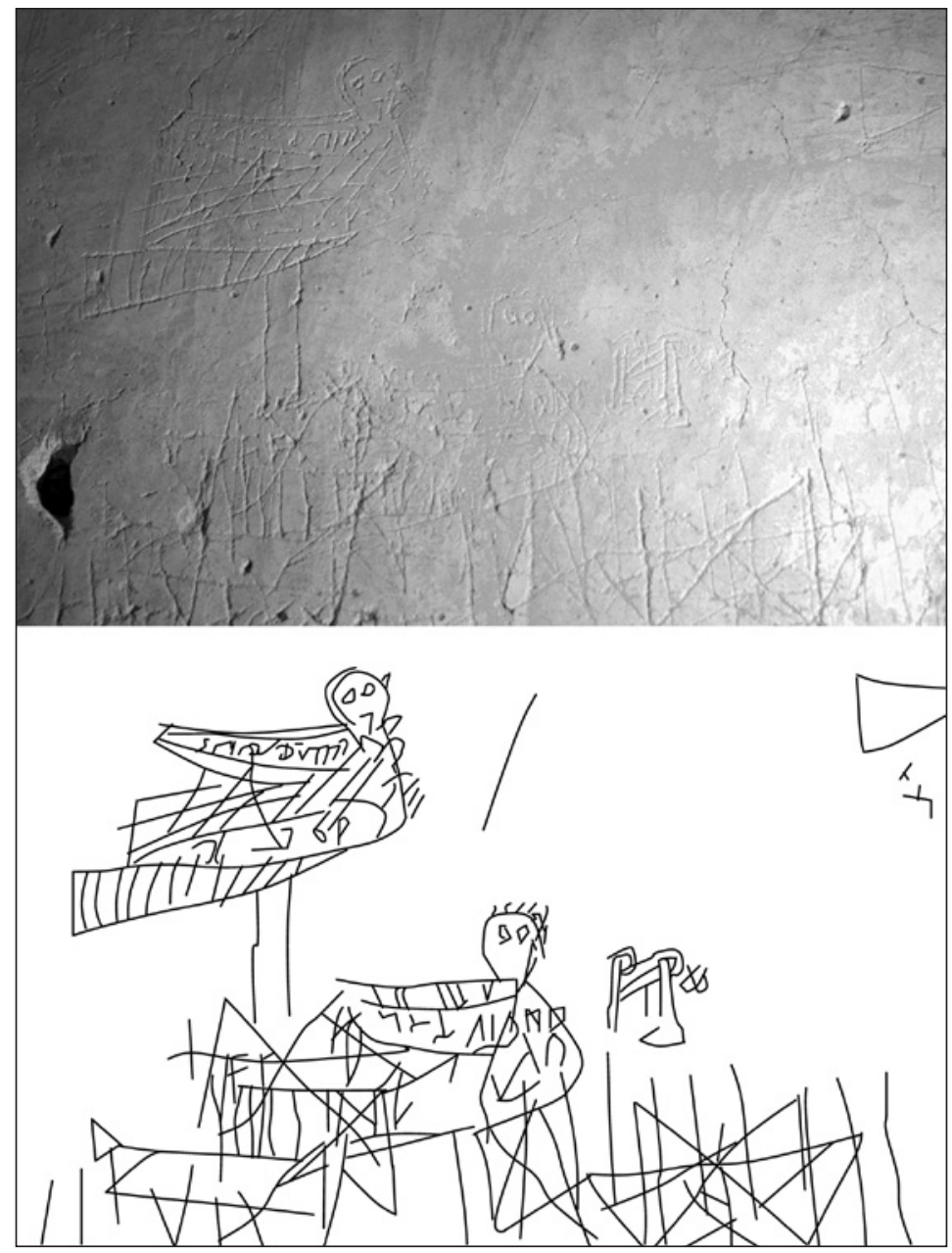

47 Esta miniatura aparece recogida en John Williams, La miniatura española en la Alta Edad Media, ed. Casariego, Madrid, 1987, p. 51. 
El hecho de tratarse de un pájaro con cabeza humana le llevó a Guardia Pons a identificar estas figuras con la sirena-pájaro que encarnaría "el pecado de la lujuria $\mathrm{y}$, de un modo más amplio, el engaño herético y los placeres del mundo incluyendo la música profana"48. Bien es cierto que la mujer-pájaro medieval, monstruo que deriva de la mujer-pez de la tradición antigua ${ }^{49}$, es una figura formada a partir de la combinación del cuerpo de ave y cabeza o torso femenino, sin embargo, en este caso no tenemos ningún elemento que nos indique el género al que pertenece esta cabeza, ya que no tiene un rostro definido o una larga melena como suele ser frecuente en estas representaciones ${ }^{50}$.

De la misma manera, en dos capiteles pertenecientes a las iglesias románicas de San Martín de Fonzaleche (La Rioja) y del Rivero (San Esteban de Gormaz) se han recogido otros casos similares de pájaros con cabeza humana que no se corresponden con la representación clara de una sirena. En el primer ejemplo, Monteiro Arias identifica los relieves con posibles sirenas-ave con muchas reservas, pues, al igual que en Santiago de Peñalba, "su talla sumaria no nos proporciona ningún detalle más"51, mientras que para el segundo caso apunta una clara influencia musulmana que encontraría su origen en "un hadiz atribuido a Abdalá Benomar, compañero de Mahoma, en el que se especifica que los condenados de la cuarta morada infernal no tienen ojos y sí alas" 52 . Explica que, al igual que en el caso de Peñalba, "su rostro parece humanizado" y posee la peculiaridad de tener las cuencas oculares vacías, hecho que no se debe "a una simplicidad esquemática de la escultura, sino que parecen responder a una iniciativa deliberada por representar a los animales sin estos órganos" ${ }^{53}$. Además, como ya hemos apuntado con anterioridad, algunas de las cabezas de las aves de Peñalba parecen portar algún tipo de tocado representado a partir de líneas

\footnotetext{
48 Milagros Guardia Pons, "Los grafitos..., p. 57.

49 Un estudio detallado sobre este híbrido se encuentra en Jacqueline LeclercQ-MarX, "Los monstruos antropomorfos de origen antiguo en la Edad Media", Anales de Historia del Arte, vol. extra. (2010), pp. 259274. Véase también la entrada Sirène en Fernand Cabrol y Henri LecrercQ, Dictionnaire d'archéologia..., vol. 15/I.

50 Sáez Rodríguez explica que las "arpías y sirenas-pájaro en principio poseían sólo cabeza femenina pero paulatinamente fueron adoptando brazos humanos, pecho, torso, caderas e incluso muslos en su parte superior imitando el cuerpo de la mujer". En época románica, las sirenas "suelen aparecer con rostro bello y lleno de carnes, cabello flotante y ondulado como una red afrodisíaca o trampa de voluptuosidad, cabeza descubierta o cubierta mediante paños o tiaras y a veces largas trenzas, alas plegadas al cuerpo o desplegadas llenando toda la superficie, y garras de ave que sujetan el astrágalo. El rostro es generalmente femenino pero en época tardía también los hay varoniles y barbados, de sexo masculino". Minerva SÁenz Rodríguez, "La imagen de la mujer en la escultura monumental románica de La Rioja", Berceo, 147 (2004), pp. 153-154 y 157.

51 Inés Monteira Arias, "La influencia islámica en la representación zoomorfa del románico soriano: Las aves y su relación con la eboraria musulmana", Codex Aquilarensis: Cuadernos de investigación del Monasterio de Santa María la Real, 21 (2005), pp. 162-163.

52 Además, advierte de la influencia islámica que presenta una figura masculina con cuerpo de ave que porta un turbante sobre su cabeza. Inés Monteira Arias, "La influencia..., p. 99.

53 Inés Monteira Arias, "La influencia..., p. 99.
} 
dispuestas en torno a ellas de forma radial, similares a las que componen el turbante del personaje masculino con cuerpo de ave de la iglesia del Rivero ${ }^{54}$.

La presencia de una imagen perteneciente a la iconografía musulmana en un contexto cristiano no es un hecho extraño, ya que durante la Edad Media Hispana existió una importante "contaminación cultural" entre el Islam y el Cristianismo ${ }^{55}$, siendo ejemplos de ello las imágenes con las que fueron decorados algunos objetos, así como los intercambios de artículos de distinta índole entre cortes de distinto signo religioso, entre otros. En este sentido podemos citar la arqueta chapada en marfil conservada en el museo Victoria y Alberto de Londres ( $n^{\circ}$ 603/1902), la cual posee en la zona baja de la cubierta una inscripción en árabe y en los lados menores un ave con cabeza humana y nimbo crucífero ${ }^{56}$. De la misma manera, la arquitectura también es permeable a estas influencias y algunos autores han aseverado que en Santiago de Peñalba, como en otros edificios del momento, se utilizaron elementos y técnicas de clara procedencia hispano-musulmana como el procedimiento del pulido o bruñido de las pinturas, los arcos de herradura enmarcados con alfiz de la puerta de entrada o los modillones de rollos que siguen modelos cordobeses ${ }^{57}$. Más marginales, tanto en ubicación como en tamaño, son los dos cuadrúpedos que aparecen en el muro norte, uno de los cuales parece la representación de un bóvido con una pentalfa en su cuerpo, así como la escena de caza que aparece representada en el muro sur y a la que ya nos hemos referido en el apartado dedicado a las estrellas de ocho lazos.

\subsection{Motivos Antropomorfos}

Las figuras humanas incisas conforman un amplio grupo. Aunque la mayor parte aparecen representadas de forma aislada, en otros casos están asociadas a algunos animales.

En el muro norte encontramos unos antropomorfos de muy pequeño tamaño y que responden a tres pequeños rostros con un incipiente cuerpo que, todo indica, nunca llegó a terminarse. Los rasgos faciales fueron solucionados de forma sencilla mediante líneas en forma de V más o menos abiertas para insinuar nariz y cejas, una escueta incisión representaría la boca y dos hendiduras las cuencas oculares. Mientras en uno de los casos el hombre está calvo y su cabeza enmarcada por sendos mechones de pelo insinuados con las correspondientes líneas paralelas, en el restante el hombre parece portar algún tipo de tocado sobre su cabeza, aunque también puede ser simplemente una ilusión óptica creada por las abundantes grietas en la pared. Guardia Pons identifica al primero de ellos con un monje tonsurado ${ }^{58}$, teoría que, aunque no confirmamos, admitimos como posible.

\footnotetext{
54 Algunas de las aves de Santiago de Peñalba parecen tener una inscripción en sus alas en caracteres que recuerdan a las grafías árabes. No obstante, ha sido imposible demostrar este hecho.

55 Inés Monteira Arias, "La influencia..., pp. 98 y 105.

56 José FerRandis, Marfiles árabes de Occidente, ed. Imprenta E. Maestre, Madrid, 1940, t. II, pp. 42 y 133.

57 Milagros Guardia Pons, "De Peñalba...", pp. 121 y 126 y Artemio Manuel Martínez Tejera, La ecclesia ..., pp. 143-166.

58 Milagros Guardia Pons, "Los grafitos..., p. 58.
} 
Según Champion, los graffiti de rostros humanos son muy frecuentes en el periodo medieval y post-medieval ${ }^{59}$, pero, sin lugar a dudas, los antropomorfos más destacables de todo el conjunto de grabados son las figuras masculinas representadas en la parte inferior del muro sur. De los seis graffiti, cuatro de ellos no son figuras humanas completas sino fragmentos anatómicos de brazos y cabezas y únicamente dos de ellos poseen un cuerpo humano completo, aunque de entre estos últimos sobresale aquel de tamaño superior y mayor definición y perfección en su factura (Fig. 10). De ello concluimos que cinco de los seis graffiti pudieron ser realizados como ensayos previos al grabado definitivo.

Esta figura principal es la representación de un hombre que ostentaría un cargo religioso, a tenor de su atuendo y la posición de sus manos, las cuales parecen estar en actitud de bendecir. La figura está ataviada con un manto con capucha apuntada y una túnica decorada con franjas verticales y horizontales que poseen una gran similitud con la decoración de las vestiduras coptas ${ }^{60}$, así como con aquellas que cubren a los obispos en las miniaturas medievales ${ }^{61}$. En la parte posterior de su calzado, a la altura de los talones, aparecen unas líneas horizontales que Guardia Pons ha identificado con unas espuelas y de las que dice que aluden a los desplazamientos a caballo que tenían que hacer los monjes desde Peñalba a otros lugares ${ }^{62}$. Bien es cierto que los acicates fueron muy usados desde la Alta Edad Media en la monta a caballo ${ }^{63}$, sin embargo, a tenor de la observación detallada que hemos realizado a un sinfín de manifestaciones artísticas de la época, podemos asegurar que comienzan a ser representados a partir del siglo XI, aunque nunca formando parte del atavío de un religioso ${ }^{64}$.

59 Matthew Champion, "Medieval graffiti..., p. 202.

60 Dibujos similares se encuentran en María Luz Mangado Alonso, El Nilo cristiano. Relaciones y tradiciones orientales en el cristianismo occidental, ed. Verbo Divino, Navarra, 2012, p. 105. "La dalmática reemplazó en la Edad Media al colobe, que era una túnica que apenas llegaba a media pierna y provista de mangas hasta el codo. Se dice que el colobe era la túnica de los apóstoles. La dalmática como túnica talar, era considerada en la Roma antigua vestimenta afeminada y hasta el siglo XII estaba provista de capuchón". Amparo García Cuadrado, Las Cántigas: el códice de Florencia, ed. Editum, Murcia, 1993, p. 129.

${ }_{61}$ Véanse las miniaturas de algunos códices medievales como El Vigilano. De la misma manera Galván Freile identificó como tales a dos de los tres personajes masculinos que aparecen representados en la escena de unción regia en el Antifonario de la Catedral de León y que poseen este tocado apuntado. Además, Galván señalaba que uno de los obispos representados tiene una sus manos adelantada "hacia la cara del monarca, en una actitud similar a la de bendecir", como en el caso que nos ocupa. Fernando Galván Freile, "La representación de la Unción Regia en el Antifonario de la Catedral de León", Archivos Leoneses, 97-98 (1995), pp. 142-143. En el monasterio de la Oliva también existe un graffito antropomorfo que ha sido identificado con un obispo o abad, ya que porta un báculo y está tocado con una mitra, el cual está recogido en Pablo OzCÁRIZ GiL, Los grafitos de la iglesia del monasterio de la Oliva (Navarra), ed. Dykinson, Madrid, 1998, pp. 98-99 y Pablo OzCÁrIz Gı,, "El estudio de los grafitos históricos de Navarra", La memoria en la piedra. Estudios sobre grafitos históricos, Pablo Ozcáriz Gil (coord.), ed. Gobierno de Navarra, Navarra, 2012, p. 22.

62 Milagros Guardia Pons, "Los grafitos...", p. 33.

63 Alejandro García-Álvarez Busto, "La topografía funeraria del monasterio de Corias en la época medieval a partir de la arqueología y las fuentes escritas", Territorio, Sociedad y Poder, 7 (2012), p. 145.

${ }^{64}$ Suelen aparecer portándolas personajes vinculados, de una u otra manera, con escenas belicosas. Tal es el caso de la representación del Goliat que lucha con el David en las pinturas murales del siglo XII de Santa María de Taull (Lérida) o "Los cuatro jinetes del Apolcalípsis" del Beato Ryland (Manchester) del siglo XIII. Imágenes recogidas en Jordi CAMPS i Montserrat PAGĖs, Guia visual art romanic. Museu Nacional d'art de 


\section{FIGURA 10}

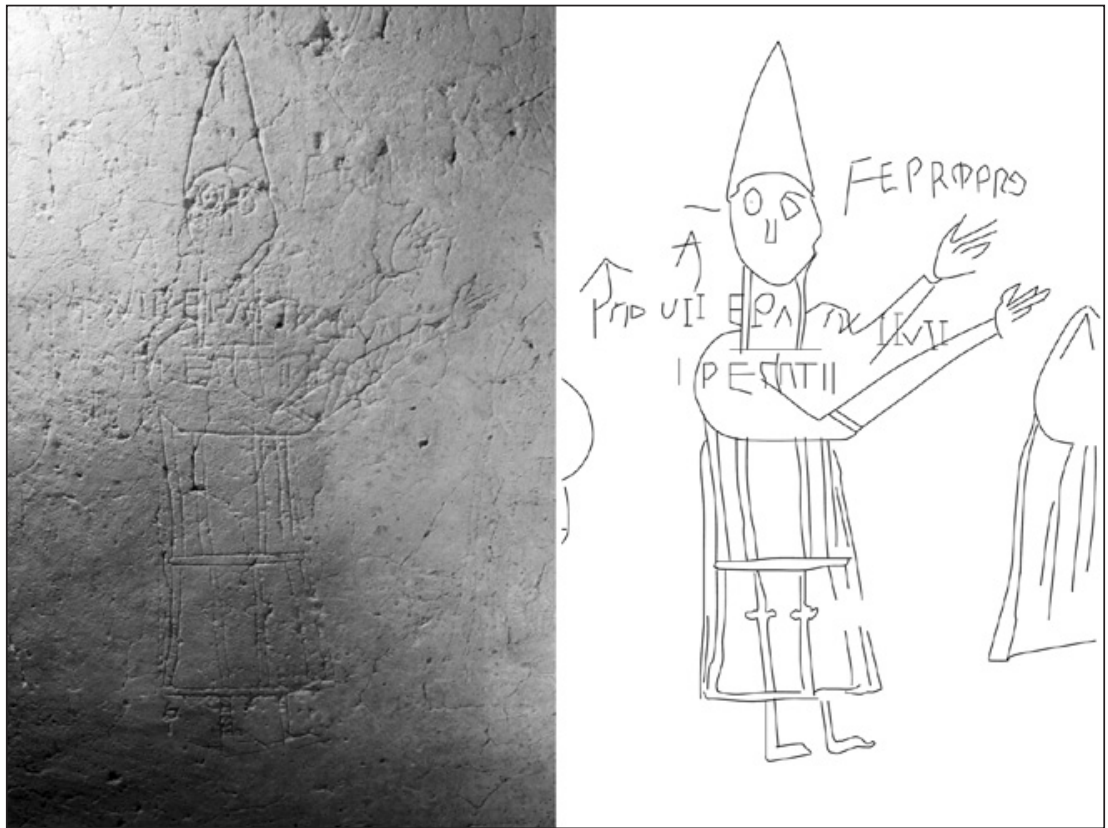

Lamentablemente, este graffito no está acompañado por un nombre propio que nos facilitase su correcta identificación, aunque Guardia Pons ha transcrito las grafías practicadas a la izquierda del personaje como FERRO[US] P[RES]B[TER]O. Ciertamente, en las fotografías que hemos tomado de este grabado se perciben unas letras incisas acompañadas de la abreviatura PBO. Sin embargo, cuando en repetidas ocasiones hemos cotejado in situ esta posible transcripción, nuestra suposición se ha desvanecido al comprobar que sobre la pared tan sólo constan las letras $F E$, seguidas de una serie de incisiones muy desvaídas y absolutamente ilegibles. Es por ello que no podemos plantear ninguna hipótesis sobre su identidad, pero, de tratarse de la representación de un obispo, la documentación histórica nos permitiría acotar algunos hombres que ostentaron este cargo y que habitualmente aparecen asociados a Santiago de Peñalba. El caso más evidente es el de Genadio, obispo de la Diócesis y fundador de este monasterio ${ }^{65}$, pero también debemos hacer mención a uno de sus discípulos, Salomón, obispo de la misma jurisdicción durante el reinado de Ramiro II y abad de Santiago de

Catalunya, ed. Museo Nacional de arte de Cataluña, Barcelona, 2005, $3^{\text {a }}$ ed., p. 77 y John Williams, The ilustrated beatus. A corpus of the illustrations of the commentary on the Apocalypse. Twelfth and thirteenth centuries, ed. Harvey Miller, Londres, 2003, vol. 5.

65 Augusto Quintana Prieto, Peñalba. Estudio histórico sobre el monasterio berciano de Santiago de Peñalba, ed. Nebrija, León, 1978, $2^{\text {a }}$ ed., p. 11 y Artemio Manuel Martínez Tejera, "La iglesia de Peñalba de Santiago. El Bierzo, León”, Argutorio, 26 (2011), p. 44, entre otros. 
Peñalba en el año $939^{66}$, o Pedro Andrés, tesorero y Deán de la Catedral de Astorga, y abad de Peñalba a finales del siglo XII ${ }^{67}$. De éste último, Augusto Quintana señalaba que "debía entender muy poco de la vida monástica. Él sabía más del manejo de las armas y del fragor de los combates" y

"que es la representación más genuina y alta que encontramos, dentro del episcopado astorgano, de aquel espíritu belicoso y aventurero que alentaba a nuestros Prelados de la Edad Media y que les llevaba a permanecer de continuo en pie de guerra al lado de los monarcas y al frente de sus mesnadas aguerridas" ${ }^{\prime 68}$.

Esta noticia permitiría establecer una posible identificación que concuerda más con la representación que estamos examinando, ya que explicaría su atuendo con espuelas, muestra de su carácter militar, y concordaría con una cronología en la que este instrumento de monta aparece con frecuencia en diferentes representaciones artísticas. Y a este mismo Pedro Andrés podríamos poner en relación con los graffiti que reproducen el nombre PETRVS en letra carolina en diversas ocasiones en ambos muros.

Por otro lado, las asociaciones entre antropomorfo y zoomorfo tienen lugar entre hombre y caballo en tres ocasiones, representaciones habituales, sobre todo, durante la Baja Edad Media ${ }^{69}$. El jinete representado en el muro norte bajo la figura del bóvido se limita a una silueta sujetando las riendas sobre un caballo que parece ataviado con una gualdrapa, a juzgar por las líneas incisas sobre parte de su cuerpo. El perfil de la cabeza del equino es muy semejante a la de aquel sobre el que cabalga Alfonso X en el fol. 71r. del Tumbo $A$ del Archivo de Compostela, datado en el siglo XIII ${ }^{70}$, mientras que en el ámbito de los graffiti encontramos similitudes con aquellos realizados sobre la parte baja de la fachada meridional de la iglesia catalana de San Juan de Boí ${ }^{71}$.

66 Augusto Quintana Prieto, Peñalba..., p. 28, Artemio Manuel Martínez Tejera, "La iglesia...”, pp. 44-45 y Artemio Manuel Martínez Tejera, La ecclesia..., p. 54, entre otros.

67 Augusto Quintana Prieto, Peñalba..., pp. 126-127.

68 Augusto Quintana Prieto, Peñalba..., pp. 126-127.

69 Esta cronología ya fue señala para los graffiti de équidos realizados en San Miguel de Escalada en Vanessa JiMENo GuERRA, “A propósito de...”, pp. 285-286. Existen graffiti de équidos realizados en fechas altomedievales, como el caso de aquel realizado en la iglesia rupestre de Las Gobas 6 C (Laño) pero de factura mucho más esquemática y tosca. Vid. Agustín Azkarate Garai-Olaun e Iñaki García Camino, Estelas e inscripciones medievales del País Vasco (Siglos VI-XI), ed. Gobierno Vasco, Bilbao, 1996, pp. 59-60. En cuanto a la representación del caballero en la plástica medieval véase algunas obras básicas como Ángel Apraiz, "La representación del caballero en las iglesias del Camino de Santiago", Archivo Español de Arte, 16 (1941), pp. 384-396; René CROzET, "Nouvelles remarques sur le cavaliers sculptés ou peints dans les eglises romanes", Cahiers de civilisation médiévale, 1 (1958), pp. 27-36; René Crozet, "Le thème du cavalier victorieux dans l'art roman de France et d'Espagne", Principe de Viana, 124-125 (1971), pp. 125-143 y Margarita Ruíz Maldonado, El caballero en la escultura románica de Castilla y León, Universidad de Salamanca, Salamanca, 1986, entre otros.

70 Esta imagen es recogida en Ramón Yzquierdo Perrín, "La miniatura en Galicia en la Baja Edad Media", La miniatura y el grabado en la Baja Edad Media en los archivos españoles, María del Carmen Lacarra Ducay (coord.), ed. Institución Fernando El Católico, Zaragoza, 2012, p. 114.

${ }_{71}$ La portada románica de San Juan de Boí se conserva en el Museo Nacional de Arte de Cataluña (MNAC) y, en ella, hemos podido hallar, entre otros, caballos incisos y una inscripción gótica junto a ellos. 
Si bien esta representación es de una factura muy simple y esquemática, mayores complicaciones reviste la identificación del jinete a caballo grabado a poca distancia de éste entre las patas de uno de los leones. Tan sólo nos percatamos de su existencia gracias a la dirección que adoptan las bridas del caballo que monta y que nos dirigen hacia unas confusas incisiones que se corresponderían con el cuerpo del caballista en cuestión. Esta representación podría completarse con una segunda figura masculina incisa frente al caballo y que, por la morfología de su tronco, parece portar un objeto de gran tamaño y de forma ovalada con el que cubre su cuerpo y que identificamos con un posible escudo, aunque su decoración a base de retículas bien pudiera indicar que se trata de algún tipo de $\operatorname{cota}^{72}$. Un ejemplo inciso de hombre en pie junto a un caballo, aunque de factura mucho más tosca y abocetada y sin escudo, se encuentra en la iglesia del monasterio de la Oliva acompañado por una inscripción gótica ${ }^{73}$.

Mucho más compleja y de mayor tamaño es la representación del muro sur, aunque su estado de conservación no es mucho mejor. La gualdrapa del caballo es mucho más evidente y está más acentuada mediante una composición lineal en torno a la panza. A este binomio le acompaña la frase en letra gótica AVE MARIA VIRGEN PURA, lo que constituye un buen ejemplo de la relación entre el caballero medieval y la religión católica. Si bien, en palabras de Vallejo Naranjo, Cristo representa "el símbolo caballeresco por excelencia, la máxima jerarquía a la cabeza de un ejército celestial comandado por san Miguel y formado en sus huestes por santos caballeros cuyo patrón es san Jorge", la Virgen María es "la gran dama cuya sola virtud vence al pecado y a la que se rinde pleitesía caballeresca, mientras ella, contemplativamente, intercede por sus protegidos" ${ }^{\text {"74 }}$. De esta conexión entre el mundo profano y el mundo religioso también da cuenta el graffito conservado en la iglesia del monasterio de la Oliva (Navarra) en el que a un hombre a caballo le acompaña una inscripción con caracteres góticos que dice $P R O$ GRA(tia) DIVINA 75 . Igualmente, son abundantes las espadas de época medieval conservadas en las diversas instituciones españolas que evidencian esta vinculación, como aquella datada a finales del siglo XIV y realizada en bronce dorado que conserva el Museo Arqueológico Nacional de Madrid sobre cuya empuñadura se realizó la inscripción DOMINE MEI/AVE MARIA GRATIA PLENA ORA PRO NOBIS con el objeto de obtener protección divina para aquel que la portase ${ }^{76}$, e incluso existen otras en cuyas

\footnotetext{
72 Una completa información sobre este elemento defensivo se encuentra en Enrique De Leguina, Glosario de voces de armería, ed. Librería de Felipe Rodríguez, Madrid, 1912, pp. 270-279.

73 El autor recoge los tres elementos como motivos aislados pero plantea la posibilidad de que todos ellos pertenecieran a una misma escena, opinión que compartimos. Pablo Ozcáriz Gil, Los grafitos..., pp. 49 y 51. En el caso de Peñalba, junto a este grupo de figuras existe una inscripción en letra gótica totalmente ilegible que es posible que estuviera vinculada con ellas.

74 Carmen Vallejo Naranjo, "Lo caballeresco en la iconografía cristiana", Anales del Instituto de Investigaciones Estéticas, 93 (2008), pp. 42-43.

75 Pablo OzCÁriz Git, Los grafitos..., pp. 70-71.

76 Otras espadas presentan otras inscripciones tales como "AVE MARIA GRATIA PLENA; IN TE DOMINESPERAVI, IN MOMINE DOMINI, etc." que, en algunos casos, "quedaban reducidas a las iniciales de las mismas". Germán Dueñas Beraiz, "Las armas: defensa, prestigio y poder", Hojas Didácticas del Museo Arqueológico Nacional (Pieza del Mes), Ciclo 2003-2004, ed. Museo Arqueológico Nacional, Madrid, 2004, p. 2.
} 


\section{FIGURA 11}

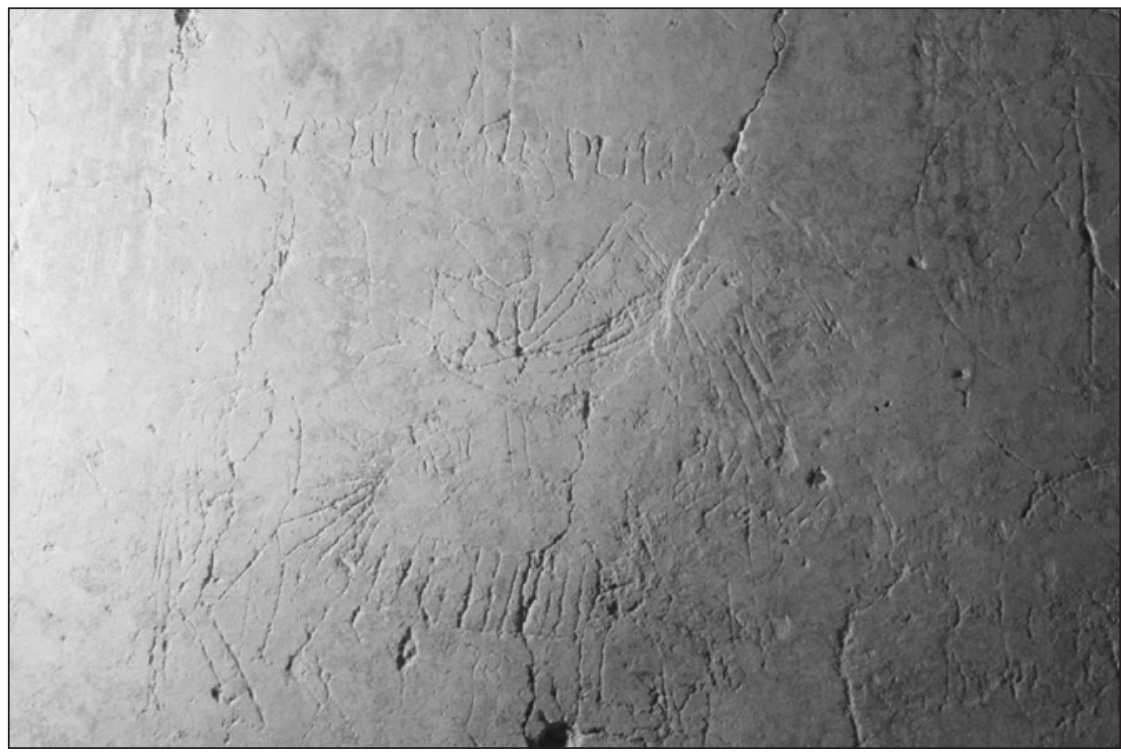

empuñaduras que se introducían reliquias cristianas ${ }^{77}$, como la famosa Durindana de Roldán $^{78}$. Por tanto, nos encontramos ante una clara introducción del mundo caballeresco dentro de la iconografía cristiana de la Baja Edad Media en un intento de la Iglesia por "conciliar su doctrina con la realidad político-militar en la que vive"79.

Atendiendo ahora al atavío del equino, la gualdrapa que portan los tres animales es un elemento que nos ayuda a establecer una fecha post quem para estos grabados ya que, recogiendo las palabras de Viollet le Duc, este tipo de cobertura larga se registra a partir

\footnotetext{
77 Vallejo señala que esta práctica es "el equivalente a la costumbre pagana de incrustar piedras mágicas, llamadas "piedras de vida»". Carmen Vallejo Naranjo, La caballería en el arte de la Baja Edad Media, ed. Universidad de Sevilla, Sevilla, 2013, p. 44. Dueñas Beraiz también indica que "a muchas de ellas se les atribuyó virtudes casi mágicas, como puede derivarse de la inclusión de reliquias en los huecos de los pomos" en Germán DueÑas Beraiz, "Las armas..., p. 5.

78 "Tuvo fama la espada de Roldán de hallarse encantada y ser una de aquellas circeas que figuran en los libros de caballerías, atribuyéndose esa cualidad a las reliquias engastadas en su empuñadura, compuestas de un diente de San Pedro, sangre de San Basilio, cabellos de San Dionisio y parte del vestido de la Virgen, por lo que deable mal faire ne li puet, dice la Chanson de Roland". Enrique de Leguina, Glosario de..., pp. 401-402.

79 Carmen Vallejo Naranjo, La caballería ..., pp. 145-146. A este tenor, para el caso de las representaciones de caballeros en San Millán de Suso (La Rioja), Ibáñez y Lejarrága explican que "la presencia de un caballero armado en un recinto sagrado en la Edad Media no es nada extraño; sobre todo si lo identificamos con el Caballero de Cristo. Figura tan presente en la Edad Media en la literatura, en el arte y en la vida misma con las órdenes de caballería". Miguel Ibáñez Rodríguez y Teodoro Lejarrága Nieto, Los grafitos..., p. 21.
} 
del año $1220^{80}$, afirmación que, junto a las grafías góticas que aparecen acompañando a una de las representaciones y los múltiples ejemplos incisos registrados en otras partes de la geografía ${ }^{81}$, nos permite asignarles una cronología bajomedieval.

\subsection{Motivos Epigráficos}

En el año 2011 abordamos el estudio de los graffiti epigráficos del templo de San Miguel de Escalada, en el que descubrimos varios relacionados con el nombre del santo titular, así como el de varios monjes que integraban el cenobio ${ }^{82}$. Este hecho lo volvemos a comprobar en la iglesia de Santiago de Peñalba. El caso más evidente es el de aquellos grabados que reproducen en escritura visigótica el nombre del obispo de la diócesis de Astorga y promotor de la construcción, Genadio ${ }^{83}$, el cual aparece inciso como $G \bar{E} N A D I I$ hasta en cinco ocasiones de forma dispersa a lo largo del muro norte. Juan es otro de los nombres inscritos con el mismo tipo de grafía en ambos muros, como IOVИN IO[ilegible]NNE en el muro norte y IOAINS en el muro sur ${ }^{84}$, y que podría tratarse de aquel que fue abad entre los años 928 y 936 del cercano San Pedro de Montes ${ }^{85}$, cenobio que formaba parte de la red de fundaciones genadianas junto con San Andrés de Montes y Santiago de Peñalba ${ }^{86}$, al igual que Nuño Menéndez, quien lo fue entre 1216 a $1222^{87}$ y cuyo nombre podría ser el que aparece grabado en muro sur en varias ocasiones en letra carolina como NUNO y NUNOM.

Abad de Santiago de Peñalba también lo fue Rodrigo a mediados del siglo XII, quien podría ser el artífice del graffito RODERICUS ME FECIT, realizado en escritura carolina en la parte baja del muro norte sobre unas líneas a modo de pautado ${ }^{88}$. Aunque Guardia Pons rechaza la posibilidad de que el propio abad de un cenobio actuara como el rogatario de una inscripción ${ }^{89}$, nosotros planteamos este hecho como algo factible, ya que existe un ejemplo documental que lo atestigua debido a que, en el ámbito paleográ-

\footnotetext{
80 Eugène Viollet Le Duc, Encyclopédie médiéval, ed. Heimdal, Bayeux, 1978, p. 356, t. I: Architecture. 81 A tenor de los graffiti de caballos con bridas registrados en el templo de San Miguel de Escalada, nos hacíamos eco de otras representaciones similares y apuntábamos una cronología bajomedieval para este tipo de imágenes. Vid. Vanessa Jimeno Guerra, “A propósito..., pp. 285-286. También pueden consultarse otros graffiti caballerescos de cronología bajomedieval en Rosa Lluch Bramon, "Uns grafits a la Pia Almoina de Banyoles", I Congrés International de Gravats Rupestres i Murals, Joan-Ramón González Pérez (coord.), ed. Institut D'Estudis Illerdencs, Lleida, 2003, pp. 780 y 783.

82 Vanessa Jimeno Guerra, “A propósito..., p. 287.

83 En torno a la edificación de la obra y sus distintas etapas véase Artemio Manuel Martínez TEJERA, La ecclesia..., pp. 51-81.

84 Tan sólo reproducidos las letras más evidentes.

85 Ernesto Zaragoza I Pascual, "Abadologio del monasterio de San Pedro de Montes", Archivos Leoneses, 74 (1983), p. 317.

86 Para más información sobre las relaciones de estos monasterios véase Iñaqui MARTín Viso, "Monasterios y redes sociales en el Bierzo Altomedieval", Hispania. Revista española de Historia, 237 (2011), pp. 9-38.

87 Ernesto Zaragoza I Pascual,"Abadologio del..., p. 321.

88 Abad recogido en Augusto Quintana Prieto, Peñalba,..., p. 122-124.

89 Milagros GUARDIA PONS, "Los grafitos...”, p. 55
} 
fico, existe el caso de un abad del Monasterio de Barbadelo (Sarriá, Lugo), Vermudo Sunilanez, que en el año 995 ejerció como escriba de un documento de donación al Monasterio de Samos (Lugo ${ }^{90}$. Además, en el caso de Santiago de Peñalba no se trata de una inscripción propiamente dicha sino de un graffiti con una lacónica preparación.

El patronímico MARTINVS fue grabado en escritura carolina en dos ocasiones en el muro norte y en una sola en el muro sur, aunque no completo y dentro de un irregular enmarque preparado a tal efecto. Además de estos tres graffiti, cerca de la puerta de entrada al templo se conserva una inscripción inconclusa, en una sola línea y también en letra carolina del siglo XII, que alude a este mismo nombre y que transcribimos como MARTINUS: CITI S: ASTVRI. Interpretamos que, el hombre en cuestión sería un tal Martinus de apellido Citi y que ostentaría algún cargo en la Diócesis de Astorga, a tenor de la $\mathrm{S}$ inicial y palabra Asturi que lo acompaña y que podría ser el principio o una abreviatura de Asturicensis. No obstante, y a pesar de la documentación revisada, no se registra ningún Martinus Citi con estas características para la cronología establecida ${ }^{91}$. Con todo, es muy probable que tanto los graffiti como la inscripción hagan alusión a la misma persona, aunque no es posible demostrarlo.

Otro tipo de inscripciones son aquellas a las que las suponemos una cierta funcionalidad litúrgica, nemotécnica, pedagógica o, incluso, ilustrativa. El primer autor en poner de manifiesto esta idea fue Lorenzo Arribas en el año 2013 a tenor de aquella realizada en el muro norte y que transcribe como C[RE]DO QUE RE[S]P[ON]SIO : HOMINEM : SALVAT : [E]T: AB ETERNO : INTERITV : LIBERET (Creo esta respuesta salva al hombre y le libera de la destrucción eterna ${ }^{92}$. Sobre ella señala que se encuentra en relación con un pasaje del abad benedictino Samaragdo de Saint-Mihiel-sur-Meuse y la conceptúa como un responso en escritura carolina que, grabado en el muro del coro a partir de un pergamino existente, actuaría como recordatorio para los monjes en los momentos de oración ${ }^{93}$. Es por ello que pensamos que con este mismo objetivo fueron realizados otros graffiti epigráficos en los muros de la iglesia aunque, eso sí, de menor extensión y complejidad. Este sería el caso de las palabras VIR ERAT que fueron incisas en al menos dos ocasiones sobre el torso del obispo inciso en el muro

\footnotetext{
90 "Veremudus servus servorum Dei nom inmerito abba scripsit". Ainoa CASTRO CoRreA, La escritura..., pp. 42, 421 y 436 .

91 En el año 1169 se registra un Martinus Citiz en un donación realizada al arcediano de la iglesia de Santa María de León en José María Fernández Catón, Colección documental del Archivo de la Catedral de León (775-1230), ed. Centro de Estudios e Investigación San Isidoro, León, 1990, t. V, doc. 1551. Igualmente, en el año 1139 se recoge un canónigo de Astorga llamado Martín Zítiz en un documento de la Catedral de Astorga en Gregoria Cavero Domínguez y Encarnación Martín López, Colección Documental de la Catedral de Astorga (1126-1299), ed. Centro de Estudios e Investigación San Isidoro, León, 2000, t. II, Doc. 690. 92 José Miguel Lorenzo ArRibas, “"Translatio in..., pp. 94-99. Con anterioridad al trabajo de Lorenzo Arribas, Guardia Pons lo recoge y transcribe incorrectamente como "[...]C DOQVE:REP[RE(HE)N] SIO:HOMINEM:SALVAT:[E]T:AB ETERNO:INFERITU:LIBERET" en Milagros Guardia Pons, "Los grafitos..., pp. 54-55.

93 Es por ello que el autor sostiene que la cita debió ser copiada de un códice que contenía las Collectiones Epistolarum et Evangeliorum de Tempore et de Santis de Smaragdo "que en algún momento formó parte de la biblioteca de Santiago de Peñalba". José Miguel Lorenzo Arribas, "«Translatio in..., p. 96.
} 
sur ya referido. Estos dos vocablos podrían hacer referencia al salmo Vir erat in terra Hus del libro de Job ("Había en el país de Hus un varón”)94 que se acostumbraba a cantar durante el Ofertorio ${ }^{95}$. De la misma manera, en el muro norte aparece la palabra IVSTVS en dos ocasiones, la cual se podría relacionar con el salmo cantado JUSTUS UT PALMA FLOREBIT ("El justo, como la palma, florecerá") tomado del libro de David $\mathrm{y}$ "del que existen numerosas versiones en más de doscientos códices manuscritos, entre los siglos IX y XVII"96. El último ejemplo de este tipo es la inscripción $B E N$ $D I C A M U S$, incisa en letra carolina junto a la puerta del templo destinada a los fieles y que podría hacer alusión al BENEDICAMUS DOMINO ("Bendigamos al Señor"), una de las fórmulas de despedida u oraciones finales empleadas en los oficios cuya respuesta sería DEO GRATIAS ("Demos gracias al Señor")"97 (Fig. 12). Es por ello que su ubicación junto a la puerta no sólo actuaría como recordatorio de la oración a la salida del templo sino que, además, podría encerrar un cierto carácter exhortativo.

Este tipo de inscripciones litúrgicas no son un hecho aislado de la iglesia de Santiago de Peñalba, sino que son frecuentes en otros templos cristianos. Un ejemplo de ello es una inscripción que conserva los fragmentos del Credo, hallada en las inmediaciones de la ermita del Cristo de la Vega en Toledo, para la que Javier de Santiago plantea que se expondría públicamente con el objeto de ser usada como una ayuda responsorial para los catecúmenos en el momento del Bautismo ${ }^{98}$.

Fuera del ámbito religioso, aunque con un carácter diferente, también son conocidos algunos ejemplos de grabados rogatorios en algunos recipientes medievales usados en las comidas, inscripciones con oraciones con el objeto de ser usadas para bendecir la mesa, como un cuerno para beber de origen danés datado en siglo XV sobre el que se inscribió POTUM DEUS BENEDICAT (Dios bendiga la bebida) ${ }^{99}$.

\footnotetext{
94 Félix Torres Amat, La Sagrada Biblia. Nuevamente traducida de la Vulgata latina al español, ed. Imprenta de Don León Amarita, Madrid, 1824, p. 409.

95 Dom León Tolosa, "Clasificación del repertorio del Graduale Romanum”, Revista Musical Chilena, 86 (1963), pp. 58 у 60.

96 María Concepción PeÑas García, "El recitativo litúrgico. Los cantos del solista en la misa", En torno al canto de los solistas y de los himnos. V Jornadas de Canto Gregoriano, Pedro Calahorra Martínez y Luís Prensa Villegas (coords.), ed. Institución Fernando El Católico, Zaragoza, 2001, p. 53. Guardia Pons lo recoge como un nombre propio en Milagros Guardia Pons, "Los grafitos..., p. 55.

97 Al parecer, esta fórmula era desconocida en Roma antes del 1000 d.c., por lo que pudo originarse en la liturgia galicana. Véase, Richard H. Hoppin, La música medieval, ed. Akal, Madrid, 2000, p. 136. Sobre la antigüedad de su uso, véase también Miguel Enguid, Catecismo litúrgico: compuesto y ordenado para la mayor instrucción de jóvenes eclesiásticos, ed. Cano, Madrid, 1804, t. III, p. 276 y Gregorio LóPEZ, Las siete partidas del sabio rey Don Alonso el IX, ed. Oficina León Amarita, Madrid, 1829, t. I, p. 70.

98 Javier De Santiago Fernández, "El hábito..., pp. 94 y 325.

99 John CherRy, Las artes decorativas medievales, ed. Akal, Madrid, 1999, pp. 49 y 52.
} 


\section{FIGURA 12}

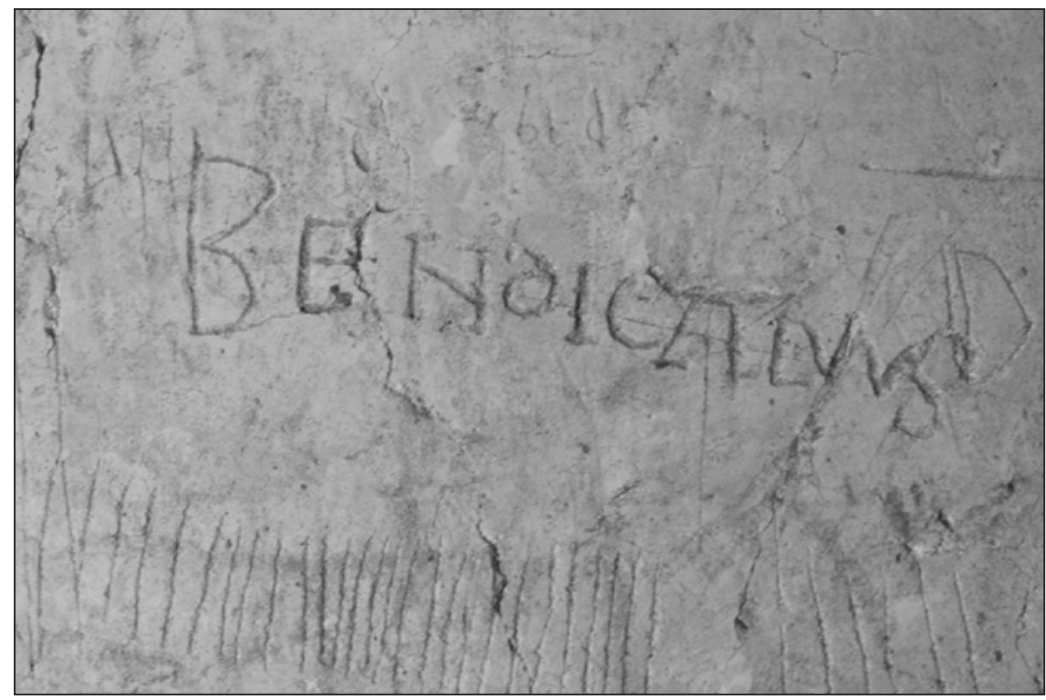

\section{A modo de conclusión}

La amplia nómina, variedad e incluso calidad de algunos de los graffiti murales estudiados en estas páginas, convierten a la iglesia de Santiago de Peñalba en un espacio de singular interés para el conocimiento de este tipo de manifestaciones parietales que deben ser considerados como un reflejo espontáneo de la vida de los moradores y visitantes de este templo. Es por ello que constituyen una importante fuente de información tanto en el ámbito artístico, a juzgar por los modelos iconográficos, símbolos representados y ensayos previos a la decoración pictórica, como en el histórico y religioso, a tenor de los nombres de personajes relevantes dentro del cenobio y las oraciones habituales en los oficios religiosos.

Asimismo, podemos concluir que la mayor parte de ellos fueron incisos a lo largo de la Edad Media, desde el siglo $\mathrm{X}$ hasta el siglo XV, y, por tanto, responden a distintos autores, manos y razones. Esta heterogeneidad de motivos, junto con su carácter circunstancial, instintivo e improvisado, no permite extraer mayores inferencias que afecten a la totalidad de su conjunto. Pero precisamente es esta disparidad la que ofrece una visión rica y variada, al tiempo que da cuenta del carácter intemporal y mutable de los edificios en los que se encuentran.

Fecha de recepción: 11 de diciembre de 2014

Fecha de aceptación: 26 de enero de 2015 
